Purdue University

Purdue e-Pubs

CTRC Research Publications

Cooling Technologies Research Center

2010

\title{
A numerical model for transport in flat heat pipes considering wick microstructure effects
}

\author{
Ram Ranjan \\ Purdue University - Main Campus \\ Jayathi Y. Murthy \\ Purdue University - Main Campus \\ S V. Garimella \\ Purdue University, sureshg@purdue.edu \\ Unnikrishnan Vadakkan \\ Intel Corporation
}

Follow this and additional works at: http://docs.lib.purdue.edu/coolingpubs

Ranjan, Ram; Murthy, Jayathi Y.; Garimella, S V.; and Vadakkan, Unnikrishnan, "A numerical model for transport in flat heat pipes considering wick microstructure effects" (2010). CTRC Research Publications. Paper 143.

http://dx.doi.org/doi:10.1016/j.ijheatmasstransfer.2010.09.057

This document has been made available through Purdue e-Pubs, a service of the Purdue University Libraries. Please contact epubs@purdue.edu for additional information. 


\title{
A Numerical Model for Transport in Flat Heat Pipes Considering Wick Microstructure Effects ${ }^{\ddagger}$
}

\author{
Ram Ranjan ${ }^{1}$, Jayathi Y. Murthy ${ }^{1}$, Suresh V. Garimella ${ }^{\S 1}$ and Unnikrishnan Vadakkan ${ }^{2}$ \\ ${ }^{1}$ School of Mechanical Engineering and Birck Nanotechnology Center \\ Purdue University \\ 585 Purdue Mall, West Lafayette, Indiana 47907 USA \\ ${ }^{2}$ Intel Corporation
}

\begin{abstract}
A transient, three-dimensional model for thermal transport in heat pipes and vapor chambers is developed. The Navier-Stokes equations along with the energy equation are solved numerically for the liquid and vapor flows. A porous medium formulation is used for the wick region. Evaporation and condensation at the liquid-vapor interface are modeled using kinetic theory. The influence of the wick microstructure on evaporation and condensation mass fluxes at the liquid-vapor interface is accounted for by integrating a microstructure-level evaporation model (micromodel) with the device-level model (macromodel). Meniscus curvature at every location along the wick is calculated as a result of this coupling. The model accounts for the change in interfacial area in the wick pore, thin-film evaporation, and Marangoni convection effects during phase change at the liquid-vapor interface. The coupled model is used to predict the performance of a heat pipe with a screen-mesh wick, and the implications of the coupling employed are discussed.
\end{abstract}

Keywords: vapor chamber, heat spreader, heat pipe model, evaporation, wick structure, electronics cooling

\footnotetext{
* Submitted for possible publication in International Journal of Heat and Mass Transfer, May 2010, and in revised form, August 2010

${ }^{\S}$ Author to whom correspondence should be addressed: 765-494-5621, sureshg@ purdue.edu
} 


\section{NOMENCLATURE}

\begin{tabular}{|c|c|c|c|}
\hline$A$ & $\operatorname{area}\left(\mathrm{m}^{2}\right)$ & $u, v$ & $\mathrm{x}-, \mathrm{y}$-direction velocities $(\mathrm{m} / \mathrm{s})$ \\
\hline \multirow[t]{2}{*}{$C$} & specific heat capacity at constant & $\vec{V}$ & velocity vector $(\mathrm{m} / \mathrm{s})$ \\
\hline & pressure $(\mathrm{J} / \mathrm{kg} \mathrm{K})$ & $W$ & width of the heat pipe (m) \\
\hline$C_{E}$ & Ergun's coefficient, 0.55 & $w$ & z-direction velocity $(\mathrm{m} / \mathrm{s})$ \\
\hline $\mathrm{Ca}$ & Capillary number $(\mu V / \sigma)$ & $x$ & axial coordinate; axial distance $(\mathrm{m})$ \\
\hline$g$ & acceleration due to gravity $\left(\mathrm{m} / \mathrm{s}^{2}\right)$ & $y, z$ & transverse direction coordinates; \\
\hline$h$ & heat transfer coefficient $\left(\mathrm{W} / \mathrm{m}^{2} \mathrm{~K}\right)$ & & transverse distance $(\mathrm{m})$ \\
\hline \multirow[t]{2}{*}{$h_{\text {evap }}$} & evaporative heat transfer coefficient & $V_{\text {cell }}$ & volume of computational cell $\left(\mathrm{m}^{3}\right)$ \\
\hline & $\left(\mathrm{W} / \mathrm{m}^{2} \mathrm{~K}\right)$ & Greek & \\
\hline$h_{f g}$ & latent heat $(\mathrm{J} / \mathrm{kg})$ & $\alpha$ & thermal diffusivity $\left(\mathrm{m}^{2} / \mathrm{s}\right)$ \\
\hline$k$ & thermal conductivity (W/m K) & $\Delta t$ & time step size (s) \\
\hline \multirow[t]{2}{*}{$k_{\text {eff }}$} & effective thermal conductivity (W/m & $\sigma$ & liquid-vapor surface tension $(\mathrm{N} / \mathrm{m})$ \\
\hline & K) & $\hat{\sigma}$ & accommodation coefficient \\
\hline \multirow[t]{2}{*}{$K$} & permeability of the porous medium & $\rho$ & density of liquid $\left(\mathrm{kg} / \mathrm{m}^{3}\right)$ \\
\hline & $\left(\mathrm{m}^{2}\right)$ & $\varepsilon$ & porosity of the wick \\
\hline$L$ & length of the heat pipe (m) & $\theta$ & solid-liquid contact angle \\
\hline$m$ & mass flow rate $(\mathrm{kg} / \mathrm{s})$ & $v$ & kinematic viscosity $\left(\mathrm{m}^{2} / \mathrm{s}\right)$ \\
\hline$\dot{m}^{\prime \prime}$ & mass flux $\left(\mathrm{kg} / \mathrm{m}^{2} \mathrm{~s}\right)$ & $\mu$ & dynamic viscosity $\left(\mathrm{N} \mathrm{s} / \mathrm{m}^{2}\right)$ \\
\hline$M$ & mass $(\mathrm{kg})$ & Subsc & ripts \\
\hline $\bar{M}$ & molecular weight (g/mol) & $a$ & adiabatic section \\
\hline $\mathrm{Nu}$ & Nusselt number $\left(h_{n a t} L / k\right)$ & bot & bottom solid wall \\
\hline$P$ & pressure $(\mathrm{Pa})$ & $c$ & condenser \\
\hline \multirow[t]{2}{*}{$\hat{P}$} & hydrodynamic component of pressure & $e$ & evaporator \\
\hline & $(\mathrm{Pa})$ & $e q u$ & equilibrium \\
\hline$\Delta \mathrm{P}$ & capillary pressure & eff & effective \\
\hline $\operatorname{Pr}$ & Prandtl number & $i, l v$ & interface \\
\hline$q$ & heat flux $\left(\mathrm{W} / \mathrm{m}^{2}\right)$ & $l$ & iquid \\
\hline$R$ & gas constant $(\mathrm{J} / \mathrm{kg} \mathrm{K})$ & $\max$ & maximum \\
\hline $\bar{R}$ & universal gas constant $(\mathrm{J} / \mathrm{mol} \mathrm{K})$ & $N D$ & non-dimensional \\
\hline$r$ & radius $(m)$ & $o p$ & operating pressure \\
\hline$t$ & time $(\mathrm{s})$ & $P V$ & center of a computational cell in \\
\hline$T$ & temperature $(\mathrm{K})$ & & vapor \\
\hline
\end{tabular}




$\begin{array}{llll}P & \text { center of a computational cell } & v & \text { vapor } \\ r e f & \text { reference } & w & \text { wall } \\ s & \text { solid } & \text { wall } & \text { non-wet portion of the solid wall } \\ \text { sat } & \text { saturation condition } & & \end{array}$

\section{INTRODUCTION}

Miniature heat pipes and vapor chambers effectively spread and carry heat from a heatdissipating microelectronic chip to a remote location where air-cooling techniques may be deployed. These passive cooling devices transfer heat across a low temperature differential so that a safe working temperature for the chip can be maintained. As the size of electronic components continues to decrease with a simultaneous increase in heat dissipation fluxes, it is becoming increasingly necessary to optimize the shape and design of the heat spreaders for more efficient thermal management. The maximum liquid feeding flow rate that can be supported in a heat pipe wick due to capillary pressure (the capillary limit) restricts the maximum heat input that can be supported without causing dry-out. Improved heat pipe performance requires wick structures with superior wicking ability as well as enhanced thin-film evaporation characteristics. In recent work, the authors $[1,2]$ studied the wicking and evaporation characteristics of various microstructures to be used in heat pipes and concluded that sintered powder wicks have the best performance characteristics among those considered. However, models which predict the effects of various microstructures on the heat transfer performance of heat pipes have not, to our knowledge, been employed widely and are the focus of the present work.

Many numerical and analytical models have been developed to study the operation of heat pipes. Garimella and Sobhan [3] reviewed the state of the art in the understanding and analysis of a large variety of heat pipes, and also identified the respective limitations. Modeling of heat pipes is complicated by the various mechanisms of heat, mass and momentum transport prevalent in the device, viz., the capillarity of the porous medium, evaporation/condensation in the wick structure, and conduction in the solid wall, among others. Models with approximate coupling between the various transport mechanisms have been developed and have led to fair predictions of heat pipe performance. In most of these cases, the wick structure has been assumed to be a continuous porous medium and the implications of micro-scale phenomena such as thin-film evaporation and Marangoni convection in the wick pores have not been given much attention. As heat pipes and vapor chambers decrease in size, and surface-to-volume ratios increase, details of transport at the liquid-vapor interface may become increasingly important in determining heat pipe performance. 
Vadakkan et al. $[4,5]$ developed a three-dimensional numerical model to study the performance of flat heat pipes with multiple discrete heat sources. The effects of heat source strength and separation on steady as well as transient performance were studied. The wick-vapor interface was assumed to be flat and local curvature effects were not considered. Van Ooijen and Hoogendoorn [6] presented a steadystate numerical analysis of the vapor core in a horizontal flat heat pipe. Tournier and El-Genk [7] developed a two-dimensional model for the transient analysis of heat pipes. The analysis determined the radius of curvature of the liquid meniscus formed in the wick pores. Zhu and Vafai [8] studied the startup operating characteristics of asymmetrical flat-plate and disk-shaped heat pipes using analytical models. Carbajal et al. [9] used a quasi-3D numerical analysis to obtain the temperature distribution on the back side of a flat heat pipe. They demonstrated that the flat heat pipe led to a more uniform temperature distribution on the condenser side compared to a solid heat spreader. Koito et al. [10] developed a numerical model to solve the flow and energy equations in vapor chambers and estimated the capillary pressure head necessary to circulate the working fluid inside the vapor chamber.

In a recent study, Do et al. [11] developed a mathematical model for predicting the thermal performance of a flat micro heat pipe with a rectangular-grooved wick structure. They considered the effects of liquid-vapor interfacial shear stress and contact angle on device performance. Xiao and Faghri [12] developed a three-dimensional heat pipe model which accounted for heat conduction in the wall and fluid flow in the vapor core and porous wicks. Singh et al. [13] studied the effect of wick properties on the heat transfer characteristics of miniature loop heat pipes. Capillary structures with smaller pore size, high porosity, and high permeability showed better heat transfer characteristics in their experiments. Models $[14,15,16]$ analyzing the performance of heat pipes with given wick structures have also been developed. Marangoni convection under large temperature differences was shown to have a significant enhancement effect on heat transfer $[17,18,19]$. However, the present authors showed [2] that Marangoni convection in the wick pores of heat pipes does not play a significant role in enhancing the rate of evaporation heat transfer.

Most numerical models for predicting heat pipe performance do not consider the microstructurescale flow and heat transfer effects. Evaporation heat transfer from the thin liquid film near the solidliquid contact line of a liquid meniscus has been shown to account for more than $60 \%$ of the total heat transfer occurring from the meniscus $[2,20]$. In most conventional heat pipes and vapor chambers, the limiting thermal resistance is that of the wick, and the resistance due to the already-efficient evaporative heat transfer usually need not be considered. However, as device dimensions fall and wicks become thinner, liquid-vapor interface resistance may begin to play an increasingly important role in determining heat pipe performance. It is therefore important to develop heat pipe models which include the effects of microscale evaporation in wick pores on overall device performance. 
Figure 1(a) shows a schematic diagram of a flat heat pipe. It consists of a solid copper wall, a porous wick structure (sintered powders in this case, and only present in this figure on the inside of the upper wall), and a vapor core. The evaporator and condenser regions are shown on the upper wall of heat pipe in this depiction. All other external surfaces are adiabatic. The liquid and vapor flows shown in Figure 1(a) complete the fluid loop of heat pipe. Due to the high vapor pressure, a large capillary pressure is developed across the liquid-vapor interface in the wick pores of the evaporator section. The capillary pressure decreases towards the condenser section and the wet point condition (flat interface) is reached at the end of the condenser section (with complete pressure recovery assumed in the vapor). The curvature of the liquid meniscus in the wick pores is determined by the interfacial capillary pressure. High capillary pressure in the evaporator section leads to higher interfacial curvature compared to the condenser region (as shown in the insets in Figure 1(a)). The interface shape determines the extent of thin-film meniscus formation in the wick pores, which in turn determines the interfacial resistance to heat transfer. In the present work, we have coupled a micro-scale wick-level model [21] with a macro-scale device-level model in order to capture the interface curvature effects in different microstructures. This will lead to a more accurate prediction of the effect of wick microstructure on the heat pipe performance.

\section{MODEL DESCRIPTION}

In the present work, a device-level numerical model (macro-model) is utilized to compute the flow and temperature fields in a flat heat pipe, also known as a vapor chamber. The macro-model solves for the continuity, momentum and energy equations in the solid wall, wick and vapor regions of the heat pipe. The wick-vapor interface is numerically modeled as a flat interface while the wick structure is treated as a porous medium. The macro-model does not account for the curvature of the liquid meniscus formed inside the wick pores and thus ignores micro-scale details of thin-film evaporation and Marangoni convection occurring during the evaporation process. To capture these micro-scale evaporation effects, a micro-model [21] which computes the evaporation of liquid in wick microstructures is coupled with the macro-model. Details of the two models and the algorithm used for coupling the two are now presented.

\subsection{Device-level macro-model}

The device-level macro-model employed here is adapted from the work of Vadakkan et al. $[4,5]$. An equilibrium model for heat transfer and a Brinkman-Forchheimer extended Darcy model are employed for fluid flow in the wick. The transient change in vapor density due to pressurization is calculated using the ideal gas state equation. The vapor flow is assumed to be laminar and incompressible. The phase-change mass flow rate due to evaporation/ condensation, and the temperature and pressure at the liquid-vapor interface are determined using an energy balance at the interface in 
conjunction with kinetic theory and the Clausius-Clapeyron equation. The energy balance at the interface includes convection and conduction on the liquid and vapor sides. The vapor flow, and the temperature and hydrodynamic pressure fields are computed from coupled continuity/ momentum and energy equations in the vapor and wick regions, and a conduction analysis in the wall. The model assumes that the wick is saturated with liquid throughout, which is required to prevent dryout.

To accommodate transient changes in the vapor and liquid mass under the assumption of a liquidsaturated wick, the volume-averaged density of the liquid is modified based on the mass balance. The model assumes all thermophysical properties to be constant except for the vapor density, which is found from the operating pressure $P_{o p}$ and the local temperature using the perfect gas law.

\subsubsection{Governing Equations and Boundary Conditions: Macro-model}

Under the assumptions discussed above, the generalized governing equations for the wick and vapor regions may be written as shown below. The continuity equation for the wick and the vapor core is

$$
\varepsilon \frac{\partial \rho}{\partial t}+\nabla \cdot(\rho \stackrel{r}{V})=0
$$

The term $\frac{\partial \rho}{\partial t}$ accounts for mass addition or depletion in the vapor and liquid spaces. The threedimensional momentum equations in the wick and the vapor core are

$$
\begin{aligned}
& \frac{\partial \rho u}{\partial t}+\nabla \cdot(\rho \vec{V} u)=-\frac{\partial \varepsilon p}{\partial x}+\nabla \cdot(\mu \nabla u)-\frac{\mu \varepsilon}{K} u-\frac{C_{E} \varepsilon}{K^{\frac{1}{2}}} \rho|\vec{V}| u \\
& \frac{\partial \rho v}{\partial t}+\nabla \cdot(\rho \vec{V} v)=-\frac{\partial \varepsilon p}{\partial y}+\nabla \cdot(\mu \nabla v)-\frac{\mu \varepsilon}{K} v-\frac{C_{E} \varepsilon}{K^{\frac{1}{2}}} \rho|\vec{V}| v \\
& \frac{\partial \rho w}{\partial t}+\nabla \cdot(\rho \vec{V} w)=-\frac{\partial \varepsilon p}{\partial z}+\nabla \cdot(\mu \nabla w)-\frac{\mu \varepsilon}{K} w-\frac{C_{E} \varepsilon}{K^{\frac{1}{2}}} \rho|\vec{V}| w
\end{aligned}
$$

In the vapor core, permeability $K=\infty$ and porosity $\varepsilon=1$. The energy equation in the wall, wick and vapor core is

$$
\frac{\partial(\rho C)_{m} T}{\partial t}+\nabla \cdot\left[(\rho C)_{l} V T_{l}^{\mathrm{r}}\right)=\nabla \cdot\left(k_{e f f} \nabla T\right)
$$

Here $(\rho C)_{m}$ assumes different values in the wall, wick and vapor core:

$$
\text { Wall: }(\rho C)_{m}=(\rho C)_{s}
$$

Wick: $(\rho C)_{m}=(1-\varepsilon)(\rho C)_{s}+\varepsilon(\rho C)_{l}$

$$
\text { Vapor core: }(\rho C)_{m}=(\rho C)_{v}
$$

Also, $k_{\text {eff }}$ and $\rho$ are the effective conductivity and density in the region of interest and assume appropriate values in the wall, wick and vapor core. In the wick (sintered screen mesh), an effective conductivity value of $40 \mathrm{~W} / \mathrm{mK}[1,27]$ is assumed. 
The following boundary conditions are imposed on the domain (presented for a $2 \mathrm{D}$ flat heat pipe, as shown in Figure 1(a)).

1. Wick-Vapor Interface: Change of phase from liquid to vapor is assumed to occur at the wick-vapor core interface (Figure 1(a)). The interface temperature $T_{i}$ is obtained from an energy balance at the interface

$$
-k_{\text {wick }} A_{\mathrm{i}} \frac{\partial T}{\partial y}+m_{i} C_{l} T_{\mathrm{i}}=-k_{v} A_{\mathrm{i}} \frac{\partial T}{\partial y}+m_{i} C_{v} T_{i}+m_{i} h_{f g}
$$

Here, $m_{i}<0$ denotes evaporation and $m_{i}>0$ denotes condensation. The interface pressure $P_{i}$ is obtained from the Clausius-Clapeyron equation, with $P_{0}$ and $T_{0}$ being reference values:

$$
\frac{R}{h_{f g}} \ln \left(\frac{P_{i}}{P_{o}}\right)=\frac{1}{T_{o}}-\frac{1}{T_{i}}
$$

The interface mass flux is calculated using kinetic theory of gases [22]:

$$
\left(\frac{2 \hat{\sigma}}{2-\hat{\sigma}}\right)\left(\frac{\bar{M}}{2 \pi \bar{R}}\right)^{1 / 2}\left(\frac{P_{v}}{\left(T_{v}\right)^{1 / 2}}-\frac{P_{i}}{\left(T_{i}\right)^{1 / 2}}\right)=\dot{m}_{i}^{\prime \prime}
$$

The above expression has been obtained with the assumption that the mean evaporation coefficient is equal to the mean condensation coefficient, where their variation with temperature and pressure may be assumed to be small [23]. The value of accommodation coefficient $\hat{\sigma}$ in the above expression for evaporation mass transfer rate has been observed to vary over four orders of magnitude, as described in [24]. A value of unity for the accommodation coefficient has been widely used [25, 26, 27]. However, experimentally obtained accommodation coefficients have been smaller due to contamination of the surface. The accommodation coefficient has also been shown in experiments to depend on temperature $[28,29]$ and vapor pressure [30]. Badam et al. [30] reported the accommodation coefficient of water to be in the range of 0.028 to 0.15 , which was deduced from evaporation experiments performed on water with the vapor pressure kept below $1200 \mathrm{~Pa}$. Rose [31] reviewed the value of the accommodation coefficient of water and suggested that its value lies in the range of $0.5-1$. The value chosen for accommodation coefficient determines the thermal resistance offered by the liquid-vapor interface in a vapor chamber, and it is critical that this value be determined carefully via experiments. Owing to the fact that the thermal performance of a vapor chamber may be greatly affected by the chosen value of $\hat{\sigma}$, we present our analysis for two values of $\hat{\sigma}, v i z ., 0.03$ and 1 , to bracket the performance. The evaporated and condensed mass is assumed to flow normal to the interface when accounting for transport due to evaporation/condensation.

2. Wick-Wall and Vapor-Wall Interface: 


$$
u=0, v=0
$$

3. Top Wall:

$$
\begin{aligned}
& \text { Evaporator section: } k_{w} \frac{\partial T}{\partial y}=q_{e} \quad 0 \leq x \leq L_{e} \\
& \text { Adiabatic section: } \frac{\partial T}{\partial y}=0 \quad u=v=0, \quad L_{e} \leq x \leq L_{e}+L_{a} \\
& \text { Condenser section: }-k_{w} \frac{\partial T}{\partial y}=h_{c}\left(T-T_{c}\right) \quad x>L_{e}+L_{a}
\end{aligned}
$$

4. Lateral Walls:

$$
\text { Adiabatic walls: } u=v=\frac{\partial T}{\partial x}=0
$$

5. Bottom Wall: no-slip adiabatic wall.

$$
u=v=\frac{\partial T}{\partial y}=0
$$

In addition, the following initial conditions are imposed:

$$
T(x, y, 0)=T_{i} \quad P_{o p}(t=0)=P_{s a t}\left(T_{i}\right)
$$

\subsubsection{Computation of operating pressure in vapor core}

Under the incompressible flow assumption, hydrodynamic pressure differences are small as compared to the absolute operating pressure in the domain. To prevent round-off in the hydrodynamic pressure gradient computation, and to allow for system pressurization under the incompressible assumption, the pressure is split into two components:

$$
P=\hat{P}+P_{o p}
$$

The hydrodynamic component $\hat{P}$ is computed using the continuity equation through the pressure correction procedure [32]. The system pressure $P_{o p}$ is a function of time and is computed using the ideal gas law and overall mass balance in the vapor core as follows:

$$
P_{o p}=\frac{M_{v}^{o}+\Delta t\left(\sum_{\text {wick/vapor faces }}-\dot{m}_{i}\right)}{\frac{1}{R} \sum_{\text {all vapor cells }} \frac{V_{\text {cell }}}{T_{P}}}
$$


$\dot{m}_{i}$ in the above equation is interfacial evaporation/condensation mass flow rate and can be written as:

$$
\dot{m}_{i}=\left(\frac{2 \hat{\sigma}}{2-\hat{\sigma}}\right) \frac{A_{i}}{(2 \pi R)^{1 / 2}}\left(\frac{\hat{P}_{P V}+P_{o p}}{\left(T_{P V}\right)^{1 / 2}}-\frac{P_{i}}{\left(T_{i}\right)^{1 / 2}}\right)
$$

where $\hat{P}_{P V}$ and $T_{P V}$ are the hydrodynamic pressure and temperature in the vapor cell adjacent to the wickvapor interface.

\subsubsection{Computation of liquid and vapor densities}

In keeping with the incompressible flow assumption, the vapor density at a cell is computed from the system pressure as:

$$
\rho_{P}=\frac{P_{o p}}{R T_{P}}
$$

The wick may in general be unsaturated during the transient. Flow in an unsaturated wick is not resolved in this work, but instead, the mean liquid density is computed so as to conserve the liquid mass:

$$
\frac{d M_{l}}{d t}=\sum_{\text {wick/vapor faces }} \dot{m}_{i} \quad \rho_{l}=\frac{M_{l}}{\varepsilon V_{l}}
$$

The liquid mass, $M_{l}$, is computed during every time step and the mean liquid density is computed using Eqn. 21.

Additional details of the numerical method are available in $[4,5]$. The governing equations are solved in their transient form using the commercial CFD solver FLUENT [33]. A transient computation of the governing equations is necessary to set the level of pressure in the vapor domain. A steady, incompressible flow calculation with all-velocity boundary conditions does not allow the pressure level to be determined uniquely since only the gradient of pressure appears in the governing equations. The pressure level is rendered unique by initial conditions; the specification of the initial mass allows the pressure to be determined uniquely at each time step. It should be emphasized that this is not an artifact of the numerical scheme, but is a property of the incompressible Navier-Stokes equations. A detailed discussion of these issues can be found in previous work by the authors [4, 5]. Suitable user-defined functions (UDFs) have been developed to compute the evaporation/condensation mass flow rates, temperature and pressure at the wick-vapor interface, as well as the liquid and vapor densities at every time step. The attainment of steady state is identified in this work as the time at which the heat transfer rate on the condenser side reaches within $2 \%$ of the value at the evaporator.

\subsection{Wick-level micro-model}

The wick-level micro-model computes the evaporation heat transfer rate from the liquid meniscus formed in the pores of common wick structures used in heat pipes. The model considers only the top layer of wick pores, where the liquid meniscus is formed. Details of this model are available in Ranjan et 
al. $[2,21]$. An idealized two-dimensional representation of screen mesh wick structure, viz., parallel horizontal wires for screen mesh wick, is used. The model assumes a static shape for the liquid meniscus formed inside wick pores. Static liquid meniscus shapes in the given wick geometries are obtained using the program Surface Evolver [34]. Surface Evolver computes the total surface energy of a given system and the equilibrium minimum energy configuration is obtained by a gradient descent method. Details of this method can be found in [1]. With known curvature of the liquid meniscus in the wick pores, the capillary pressure generated by the wick structure (for a given wick porosity, length scale and solid-liquid contact angle) is also determined using the Young-Laplace equation. It should be noted that the meniscus level in the wick pore has been assumed to be equivalent to the radius of the wires in the present work. As presented in [1,2], this meniscus level leads to the highest capillary pressure generation in the wick pore; the evaporative heat transfer rate, on the other hand, was found to be unaffected by a change in the meniscus level. For future reference, this model is referred to as the static-meniscus micro-model.

Figure 1(b) shows the equilibrium shape of a liquid meniscus formed between parallel horizontal wires (idealized representation for screen mesh wick; only top layer is shown here). The solid-liquid contact angle is assumed to be $30^{\circ}$, the porosity is 0.56 , and the non-dimensional radius (radius taken as the length scale) of the wires is 1 .

The static liquid meniscus shapes thus computed are exported from Surface Evolver to GAMBIT [33] and the domain is discretized for finite volume computations in FLUENT [33]. It is noted that the assumption of a static meniscus shape under evaporative conditions would be valid for the very small Weber and Capillary numbers encountered in this work as is verified using simulations. The FLUENT model is used to compute flow and heat transfer in the microstructure. This model is referred to as the wick-level micro-model. The mathematical formulation for modeling evaporation in wick structures is now presented.

\subsubsection{Governing Equations and Boundary Conditions: Wick-level Micro-model}

Figure 1(c) shows the computational domain used for modeling evaporation from the liquid meniscus in wick microstructures. A unit cell representing the wick topology is modeled. Incompressible, laminar and steady flow of water with constant properties is assumed in the liquid domain. The vapor is assumed to be saturated at a given temperature, as in an operating heat pipe. The wick-level micro-model is utilized only to correct the phase change mass flow rates (Eqn. 9) at the wickvapor interface in the macro-model. The vapor domain is not modeled since the absolute mass flow rates in the heat pipe are not computed from the micro-model. The following continuity, momentum and energy equations are solved: 


$$
\begin{gathered}
\nabla \cdot \vec{V}=0 \\
0=-\nabla p+\nabla \cdot\left(\mu_{l} \nabla \vec{V}\right)-\rho_{l} \vec{V} \cdot \nabla \vec{V} \\
0=-\nabla \cdot\left[(\rho C)_{l} \vec{V} T\right]+\nabla \cdot\left(k_{l} \nabla T\right)
\end{gathered}
$$

In the solid wall, the energy equation reduces to:

$$
\nabla^{2} T=0
$$

The boundary conditions for the case of a 2D meniscus between horizontal wires are shown in Figure 1(c). The incoming liquid is assumed to be at a constant temperature, $T_{\text {inlet }}$, with a given pressure inlet boundary condition. A constant temperature boundary condition is applied at the bottom solid wall. A convective heat transfer boundary condition is imposed on the non-wetted portion of the solid particles exposed to vapor, labeled Top Wall in Figure 1(c). The value of the natural convection coefficient $h_{\text {nat }}$ from the surface of spheres and long wires is given by the Nusselt number correlation presented in [35]. The liquid-vapor interface is modeled as a fixed interface with a convective boundary condition. To promote numerical stability, the heat transfer due to evaporation is implemented through an equivalent convective heat transfer coefficient, $h_{\text {evap }}$, which is obtained using the evaporative mass flux expression (Eqn. 9), so that:

$$
h_{\text {evap }}=\frac{\dot{m}_{i}^{\prime \prime} h_{f g}}{\left(T_{i}-T_{v}\right)}
$$

Evaporation from the liquid-vapor interface is modeled under the assumption of saturated vapor conditions, simulating heat pipe operation. The evaporative mass flux at the interface is obtained according to Schrage [22] and is given by Eqn. 9. Two values for $\hat{\sigma}, 0.03$ and 1.0 are used in the micromodel computations as mentioned earlier. Mass transport due to evaporation at the liquid-vapor interface is implemented by imposing mass sink terms in the liquid cells adjacent to the interface.

Figure 2(a) and (b) show the temperature and flow fields inside the wick pore for a meniscus between parallel horizontal wires, for $\hat{\sigma}=0.03$ and 1 , respectively. The vapor is assumed to be saturated at $298 \mathrm{~K}$. Standard thermophysical properties of water at $298 \mathrm{~K}$ are used in these simulations. The liquid-vapor interface is seen to be at the minimum temperature in the whole domain due to evaporation heat transfer. Non-uniformity in the meniscus thickness leads to differential evaporation rates, and consequently, a temperature gradient along the interface. This leads to the formation of two counterrotating Marangoni vortices in the liquid domain. Evaporative mass flux on the interface (Eqn. 9), from the solid-liquid contact line to the center of meniscus, is plotted in Figure 2(c) for the two values of accommodation coefficient. The evaporative mass flux for $\hat{\sigma}=0.03$ is smaller than for $\hat{\sigma}=1$ by more than an order of magnitude. Also, for $\hat{\sigma}=1$, the evaporative mass flux decreases sharply to zero from the thin-film region towards the central meniscus. From the detailed results in $[2,21]$ obtained using $\hat{\sigma}=$ 
1, thin-film evaporation occurring near the solid-liquid contact line was found to account for more than $80 \%$ of the total evaporation from the interface. However, for $\hat{\sigma}=0.03$, it is seen in Figure 2(c) that the evaporative mass flux decreases gradually from the contact line thin-film region towards the central region. The contribution of the thin-film region itself to the total evaporation from meniscus is insignificant for $\hat{\sigma}=0.03$. The authors previously $[2,21]$ showed that Marangoni convection is insignificant in enhancing evaporation in wick pores, and therefore, heat transfer at this scale is determined to first order by thermal conduction.

The effects of changing the value of accommodation coefficient on the rate of evaporation and the evaporation heat transfer coefficient (as defined in Eqn. 26) are considered further by simulating the evaporation of water from a liquid pool, using the wick-level micro-model. The domain for this problem is shown in Figure 3(a), in which the vapor domain is assumed to be saturated at 298 K. Figure 3(b) shows the variation of evaporation rate and evaporative heat transfer coefficient with $\hat{\sigma}$. With an increase in $\hat{\sigma}$ from 0.18 to 1.6 , the evaporative heat transfer coefficient increases from $8.3 \times 10^{4} \mathrm{~W} / \mathrm{m}^{2} \mathrm{~K}$ to $3.32 \times 10^{6} \mathrm{~W} / \mathrm{m}^{2} \mathrm{~K}$. However, the evaporation rate $\left(m_{l}\right)$ increases with an increase in $\hat{\sigma}$ from 0.18 to 0.5 , but becomes independent of the value of $\hat{\sigma}$ with further increases in $\hat{\sigma}$. This shows that for higher values of $\hat{\sigma}(>0.5)$, the rate of evaporation is determined by the conduction heat transfer across the liquid pool (from inlet to the vapor domain) and the liquid-vapor interface resistance for heat transfer becomes negligible.

\subsection{Coupling of Macro- and Micro-models}

The static-meniscus and wick-level micro-models described in the previous section are coupled with the device-level macro-model in order to incorporate the effect of different microstructures on heat pipe performance. The macro-model does not account for the liquid-vapor interface shape in the wick pores, thin-film evaporation or Marangoni convection. However, it has been noted [2, 21] that thin-film evaporation effects are critical for predicting the evaporative mass flow rate correctly. Coupling the micro-models with the macro-model captures the micro-level aspects of evaporation from the liquidvapor interface and examines the importance of the liquid-vapor interface in determining the device performance for given conditions. The algorithm for coupling the two types of models is now presented.

For a given heat input to the heat pipe, the local liquid-vapor interface shape is determined by the balance of surface tension forces, viscous stresses and the pressure difference across the interface. Viscous stresses play a relatively small role, and are neglected in the current formulation. Thus, the interface shape is determined from a balance of surface tension forces and the interfacial pressure difference. It changes with location based on pressure gradients resulting from the liquid and vapor flows in the device. 
The liquid-vapor interfacial pressure drop along the heat pipe is computed using the macro-model for a given heat input and wick geometry (pore radius, porosity, permeability). Since the macro-model assumes a flat meniscus everywhere in the heat pipe, the interfacial area and mass flow rate in the macromodel must be corrected to account for meniscus curvature, and local micro-scale transport effects. This is done by comparing the evaporation mass flow rate from a curved meniscus in the wick pore with that from a flat meniscus. The comparison yields a local correction factor to the flat-meniscus evaporative mass flow rate (Eqn. 9) which is shown to be a function of the local solid-liquid contact angle and the pressure difference across the meniscus. The details of the coupling procedure are given below.

Step 1: Given a wick porosity for the heat pipe, compute the flow and temperature fields using the devicelevel macro-model. This computation yields the pressure difference across the meniscus at each location on the interface, which, in the absence of normal stresses, is the capillary pressure in the micro-model. Step 2: Develop a correlation for the effective pore radius as a function of capillary pressure using the static-meniscus micro-model. The capillary pressure generated by the wick is given by the YoungLaplace equation

$$
\Delta P=\frac{2 \sigma}{r_{e f f}} \cos \theta
$$

Here, $\sigma$ is the liquid-vapor surface tension, $\theta$ is the solid-liquid contact angle and $r_{\text {eff }}$ is the effective pore radius of wick structure. The non-dimensional effective pore radius, $r_{e f f} / r$, is therefore given by:

$$
r_{\text {effND }}=\frac{r_{\text {eff }}}{r}=\frac{2 \cos \theta}{r \Delta P}
$$

where $r$ is the radius of the wires. For a given contact angle, surface tension and microstructure, the static-meniscus micromodel [1] yields the capillary pressure $(\Delta P)$ supported by the microstructure. The non-dimensional effective pore radius is then cast as a function of contact angle and wick porosity for later use.

Figure 4 shows the variation of $r_{\text {effND }}$ with increasing solid-liquid contact angle for different wick porosities for the case of a screen wick, idealized as horizontal parallel wires. The effective pore radius of the wick does not change with the contact angle $(\theta)$ for $\theta<80^{\circ}$ and the change is relatively small for $\theta>$ $80^{\circ}$ for porosities of interest. Also, the effective pore radius increases with increasing porosity. The following correlation may be developed for $r_{\text {effND }}$, across the range of $\theta:$ :

$$
r_{\text {effND }}=16.29(\varepsilon)^{3.3985}
$$

It should be noted that the level of the liquid meniscus in a wick pore is assumed to be equal to $r$ in the correlation. The present correlation for non-dimensional effective pore radius is compared with one that is widely used in the literature $\left(r_{\text {effND }}=1 / 2 \times\right.$ pitch $)$ [27] which is also plotted in Figure 4 . The comparison shows that the correlation from the literature over-predicts the effective pore radius for smaller porosities 
(0.4) while it under-predicts the effective pore radius for higher porosities (>0.6). There is good agreement between the values predicted by the present correlation and that in literature at average porosity levels [0.5-0.6].

Step 3: Compute the local contact angle in terms of the capillary pressure from the $r_{\text {effND }}$ correlation. Using the correlation in Eqn. 29 in Eqn. 27, the local solid-liquid contact angle in the wick pores may be determined if the capillary pressure is known:

$$
\cos \theta=\frac{16.29(\varepsilon)^{3.3985} \Delta P}{2 \sigma}
$$

The capillary pressure $\Delta P$ is known from the macro-model computation in Step 1. Thus, the contact angle at any location on the interface may be computed. .

Step 4: With a known contact angle, find the area ratio $A_{\text {curved }} / A_{\text {flat }}$ and the corresponding correction factor. In this step, two computational domains are set up at the scale of the wick microstructure. They are used to obtain a correction factor which accounts for the use of a flat interface shape in the macromodel. The correspondence between the two domains is shown in Figure 5. The first incorporates the details of the wick structure and the interface shape corresponding to the contact angle of interest, as shown on the left in Figure 5. The second, shown on the right of Figure 5, represents the interface as a flat surface. The objective is to find a correction factor to the evaporative mass transfer rate (Eqn. 9) for the flat interface which yields the evaporation rate obtained by the curved interface model under the same operating conditions. The wick-level micro-model is used to obtain the detailed flow and heat transfer rates for both the domains in Figure 5.

The correction factor is given by

$$
\frac{m_{\text {curved }}}{m_{\text {flat }}}=\left(\frac{m_{\text {curved }}^{\prime \prime}}{m_{\text {flat }}^{\prime}}\right)\left(\frac{A_{\text {curved }}}{A_{\text {flat }}}\right)
$$

The above expression shows that the correction factor consists of two separate parts. The first is the correction in the mass flux, $\left(\frac{m_{\text {curved }}^{\prime \prime}}{m_{\text {flat }}}\right)$, which results from micro-scale flow and heat transfer effects such as thin-film evaporation and Marangoni convection. The second is a correction due to interfacial area, $\left(\frac{A_{\text {curved }}}{A_{\text {flat }}}\right)$. These correction factors are utilized to correct the interfacial area and phase-change mass flux in Eqns. 7 and 9.

The variation of meniscus area ratio with contact angle for various wick porosities is presented in Figure 6 (a). The ratio $\left(\frac{A_{\text {curved }}}{A_{\text {flat }}}\right)$ decreases with an increase in the contact angle and increases linearly 
with an increase in the porosity of the wick structure. It is less than unity because of the area occupied by the wire. The following correlation for area ratio as a function of porosity and contact angle (in degrees) is obtained using the least-squares curve-fit feature of MATLAB [36]:

$$
\frac{A_{\text {curved }}}{A_{\text {flat }}}=1.577 \varepsilon^{1.7043} \theta^{-0.0693}
$$

The ratios of evaporative mass fluxes in the wick pore for $\hat{\sigma}=0.03$ and 1.0 are obtained as a function of the solid-liquid contact angle and wick porosity. The vapor temperature and solid wall superheat (see $T_{b o t}$ in Figure 1(c)) are also varied to determine their effect on the mass flux ratio. The mass flux ratio changes by less than $5 \%$ for a $7 \mathrm{~K}$ variation in vapor temperature and a $15 \mathrm{~K}$ variation in solid superheat, showing that the mass flux ratio may be assumed to be unaffected by the vapor temperature and superheat.

Variations of the mass flux ratio with contact angle for various wick porosities are shown in Figure 6(b) and (c) for $\hat{\sigma}=0.03$ and 1.0, respectively. The mass flux ratio is always greater than 1; this is due to the formation of a thin-film meniscus at the solid-liquid contact line, and to a lesser extent, enhanced convection effects. The mass flux ratio decreases with increasing contact angle and porosity. This is because the thin-film area of the meniscus in a wick pore decreases with increase in contact angle and porosity. It can also be observed that the mass flux correction ratios are much greater for $\hat{\sigma}=1$ as compared to those for $\hat{\sigma}=0.03$. As it was discussed earlier (refer to the discussion regarding Figure 2(c)), thin-film evaporation effects near the solid-liquid contact line are more pronounced for $\hat{\sigma}=1$. This leads to higher mass flux corrections for $\hat{\sigma}=1$ as compared to $\hat{\sigma}=0.03$. The following correlations are obtained for the mass flux ratios as functions of contact angle (in degrees) for a porosity $=$ 0.56 using the least-squares curve-fit feature of MATLAB [36]:

$$
\begin{aligned}
& \text { For } \hat{\sigma}=1, \quad \frac{m_{\text {curved }}^{\prime \prime}}{m_{\text {flat }}^{\prime \prime}}=8.56 \exp (-0.009 \theta) \\
& \text { For } \hat{\sigma}=0.03, \quad \frac{m_{\text {curved }}^{\prime \prime}}{m_{\text {flat }}^{\prime \prime}}=2.21 \exp (-0.001 \theta)
\end{aligned}
$$

Step 5: Correct the local evaporative mass flow rate at the liquid-vapor interface in the macro-model using area and mass flux ratios. Using the capillary pressure at the point of interest on the interface, the local contact angle $\theta$ is first computed using Eqn. 30. Once $\theta$ is known, the area and mass flux corrections are computed from Eqns. 32 and 33 or 34, and the local evaporation mass flow rates in the heat pipe macro-model are corrected using Eqn. 31. The corrections are also employed in the calculation of interface temperature (Eqn. 7), and the computation of system pressure (Eqn. 18). This process is repeated during every iteration of the macro-model simulation until convergence is obtained. 


\section{RESULTS AND DISCUSSION}

Simulation results for a 2D vapor chamber (as shown in Figure 7 (a)) using the device-level macro-model and coupled micro-macro models are presented in this section. The temperature and flow fields in the vapor chamber, as predicted by the macro-model, for given input heat flux and condenser side conditions are discussed for two values of the accommodation coefficient, $\hat{\sigma}=0.03$ and 1 . This is followed by the implications of using the micro-macro coupled model for the prediction of device performance under a given set of conditions. A smaller vapor chamber with a thinner wick structure and higher wick thermal conductivity, is discussed next in order to examine the role of the liquid-vapor interface on the performance of vapor chambers as they are miniaturized.

\subsection{Description of Vapor Chamber under Study}

A schematic diagram of a 2D flat vapor chamber modeled in the present work is shown in Figure 7(a). It incorporates a $5 \mathrm{~mm}$ wide evaporator region at the center of its top surface while the entire lower surface is the condenser region. A screen mesh is assumed for the wick. The vapor chamber has a height of $3 \mathrm{~mm}$ and a length of $30 \mathrm{~mm}$. A solid wall thickness of $0.25 \mathrm{~mm}$, a wick thickness of $0.2 \mathrm{~mm}$ and a vapor core thickness of $2.1 \mathrm{~mm}$ are chosen. All surfaces other than the evaporator and condenser regions are modeled as adiabatic solid walls. The wall and wick are made of copper and the working fluid is water. The porosity, permeability and thermal conductivity of the sintered screen mesh wick are 0.56 , $2.97 \times 10^{-11} \mathrm{~m}^{2}$, and $40 \mathrm{~W} / \mathrm{mK}$, respectively. Ergun's coefficient, $C_{E}$, is taken to be 0.55 . The radius of the wires in the screen mesh is assumed to be $100 \mu \mathrm{m}$. The wick is present on all sides of the vapor chamber. The heating and cooling boundary conditions are applied on opposite sides of the chamber. An input heat flux of $10 \mathrm{~W} / \mathrm{cm}^{2}$ is applied at the evaporator region of the heat pipe, leading to a heat input of $500 \mathrm{~W} / \mathrm{m}$. Standard thermophysical properties for water and copper at $298 \mathrm{~K}$ are utilized. The thermophysical properties of the vapor chamber material and working fluid are tabulated in Table 1. The coolant water temperature and the heat transfer coefficient on the condenser are $298 \mathrm{~K}$ and $400 \mathrm{~W} / \mathrm{m}^{2} \mathrm{~K}$, respectively. The initial temperature of the heat pipe is $298 \mathrm{~K}$ and the vapor is assumed to be saturated.

\subsection{Flow and Temperature Fields inside the Vapor Chamber}

Figure 7(b-g) shows the temperature and flow fields in the vapor chamber, predicted by the macro-model for $\hat{\sigma}=1$ and 0.03 . The temperature drops across the vapor chamber for $\hat{\sigma}=1$ and 0.03 are $0.73 \mathrm{~K}$ and $1.62 \mathrm{~K}$, respectively. For the smaller value of the accommodation coefficient, the thermal resistance of the liquid-vapor interface inside the vapor chamber is significant, thus leading to a higher thermal resistance of the vapor chamber. Figure 7(b) and (c) show the temperature contours in the vapor chamber. The working liquid evaporates at the liquid-vapor interface below the evaporator region of the 
vapor chamber and the vapor condenses on the lower liquid-vapor interface. Figure 7(d) and (e) show the velocity magnitude contours and streamlines in the wick region of the vapor chamber for $\hat{\sigma}=1$ and 0.03 , respectively. For $\hat{\sigma}=1$, the maximum fluid velocity in the vapor is $0.28 \mathrm{~m} / \mathrm{s}$ which is approximately 3 orders of magnitude larger than the maximum velocity $\left(5.5 \times 10^{-4} \mathrm{~m} / \mathrm{s}\right)$ in the wick. Also, the maximum vapor velocity is higher $(0.28 \mathrm{~m} / \mathrm{s})$ in the case of $\hat{\sigma}=1$ than the corresponding value of $0.25 \mathrm{~m} / \mathrm{s}$ for $\hat{\sigma}=0.03$. The Reynolds number $\left(\frac{\rho|\vec{V}| r}{\mu}\right)$ of the flow in the wick is of the order of 0.1 , making the Darcian approach appropriate in the wick medium. The liquid pressure drops are found to be $323 \mathrm{~Pa}$ and $320 \mathrm{~Pa}$ for $\hat{\sigma}=1$ and 0.03 , respectively. The steady-state operating pressure of the heat pipe is $31.9 \mathrm{kPa}$ and $32.1 \mathrm{kPa}$ for $\hat{\sigma}=1$ and 0.03 , respectively.

Figure 8(a) and (b) show the temperature values on the outer walls of the vapor chamber for the two values of accommodation coefficient. The temperature is highest at the center of the evaporator region while that on the condenser side is uniform, as desired for a vapor chamber heat spreader. The predicted temperature drops show that the thermal resistance offered by the vapor chamber is $1.46 \times 10^{-3}$ $\mathrm{K} / \mathrm{W}$ and $3.24 \times 10^{-3} \mathrm{~K} / \mathrm{W}$ for $\hat{\sigma}=1$ and $\hat{\sigma}=0.03$, respectively. The evaporation/condensation mass fluxes are plotted along the liquid-vapor interfaces on the evaporator and condenser sides of the vapor chamber in Figure 8(c) and (d) for $\hat{\sigma}=1$ and $\hat{\sigma}=0.03$, respectively. It is seen that the working fluid evaporates from the upper liquid-vapor interface over a region approximately $1 \mathrm{~cm}$ long, which is twice the size of the evaporator heat input area. The vapor condenses uniformly over the liquid-vapor interface on the condenser side.

\subsection{Effects of micro- and macro-model coupling}

Steady-state results from the micro-macro coupled heat pipe model are presented for the 2D vapor chamber in Figure 7(a). The vapor chamber material, working fluid properties and the thermal boundary conditions used are the same as those considered in the macromodel in the previous section. The thermal performance of the vapor chamber for both values of accommodation coefficient is predicted with the coupled model and the results compared to the uncoupled macromodel.

The coupling of the micro-macro models is implemented by the means of correcting the interface mass flow rates and the interfacial area based on the interfacial capillary pressure drop inside the vapor chamber. Figure 9(a) and (b) present the interfacial pressure drop and the local contact angle along the liquid-vapor interface in the vapor chamber for $\hat{\sigma}=1$ and 0.03 , respectively. Points $1,2,3$ and 4 correspond to different locations on the liquid-vapor interface in the vapor chamber, as marked in Figure 7(a). The wet point is assumed to be at the center of the condenser region (at location 3 ) in the vapor 
chamber. The liquid pressure in the wick is highest at this location, as it would be at the end of the condenser section in a cylindrical heat pipe. The interfacial capillary pressure drop (318 Pa for $\hat{\sigma}=1$ and $317 \mathrm{~Pa} \hat{\sigma}=0.03$ ) is highest at the center of the evaporator section, leading to the highest curvature and smallest contact angle $\left(69.9^{\circ}\right.$ for $\hat{\sigma}=1$ and $\left.70^{\circ} \hat{\sigma}=0.03\right)$ at this location. The contact angle increases from $69.9^{\circ}$ in the evaporator section to $90^{\circ}$ in the center of the condenser region (i.e., at the wet point).

Figure 9(c) and (d) show the mass flux correction, area correction and mass flow rate correction ratios along the liquid-vapor interface in the vapor chamber for $\hat{\sigma}=1$ and 0.03 , respectively. The area correction ratio is predicted using Eqn. 32 while the mass correction ratios can be computed using Eqns. 33 and 34 for the two values of accommodation coefficient. As can be observed from the figures, the corrections in interface area and mass flow rate are highest at the point of highest curvature and lowest contact angle, i.e., the center of the evaporator region (point 1). The corrections become smaller as the condenser section is approached since the meniscus curvature in the wick pore decreases from the evaporator center towards the center of the condenser region. Mass flux correction ratios are higher for $\hat{\sigma}=1$ as compared to those for $\hat{\sigma}=0.03$. The total correction ratio is the product of area and mass flux correction ratios and it shows a similar variation as the mass flux correction ratio along the liquid-vapor interface in the vapor chamber. For $\hat{\sigma}=1$, the total correction ratio is greater than 1 leading to an enhancement in the evaporation/condensation rates in the vapor chamber. For $\hat{\sigma}=0.03$, the total correction ratio is smaller than 1 , thus reducing the rate of evaporation/condensation inside the chamber. With a decrease in the phase change rates, it is expected that the thermal resistance of the vapor chamber will increase when a working fluid with very small accommodation coefficient is used in the vapor chamber.

A comparison between the non-coupled and coupled models is now presented. For $\hat{\sigma}=1$, as presented in Figure 9(c), the mass flow rate correction ratios are greater than 1 (in the range of 1.4-1.6). This leads to an increase in the evaporation/condensation heat transfer coefficient at the liquid-vapor interface, thus reducing the thermal resistance offered by the interface in the device. However, as discussed at the end of section 2.2.1, the rate of evaporation from a liquid meniscus will be only slightly affected if the evaporation heat transfer coefficient is enhanced when $\hat{\sigma}>0.5$. A similar observation is made by comparing the temperature drops across the vapor chamber from the non-coupled and coupled models. The non-coupled model predicts the temperature drop across the vapor chamber to be $0.72 \mathrm{~K}$ while the coupled model predicts it to be $0.7 \mathrm{~K}$ ( $\sim 3 \%$ decrease in the temperature drop). However, for $\hat{\sigma}$ $=0.03$, the temperature drop predicted by the coupled model is $1.92 \mathrm{~K}$, while the non-coupled model predicts a temperature drop of $1.62 \mathrm{~K}$. The temperature drop predicted by the coupled model is $\sim 16 \%$ 
higher than that from the non-coupled model. The increase in thermal resistance can be explained on the basis of the mass flow rate correction ratios being smaller than 1 for $\hat{\sigma}=0.03$, as presented in Figure 9(d). Hence, the coupled model incorporates the increase in the thermal resistance of the vapor chamber by accounting for the liquid-vapor interface thermal resistance in the vapor chamber. With the coupled model, the steady -state operating pressure of the vapor chamber decreases from $31.9 \mathrm{kPa}$ (non-coupled model) to $31.8 \mathrm{kPa}$ for $\hat{\sigma}=1$. This is due to the decrease in the working temperature of the vapor chamber. However, for $\hat{\sigma}=0.03$, the working temperature of the vapor chamber increases as a result of coupling and so, the coupled model predicts the operating pressure to be $32.2 \mathrm{kPa}$ (32.1 $\mathrm{kPa}$ predicted by the non-coupled model).

Figure 10(a) and (b) show the temperature contours in the vapor chamber and the temperature values on the outer surfaces of the vapor chamber, as predicted by the coupled model for $\hat{\sigma}=0.03$.

\subsubsection{Vapor chamber with a thinner, higher-conductivity wick}

As discussed above, the coupling of the wick-level micro-model with the device-level macromodel leads to an accurate assessment of the role of the liquid-vapor interface inside the vapor chamber for determining its spreading behavior, i.e., the thermal performance. It is shown that the coupling is important for accurate predictions in the case of working fluids with small accommodation coefficients. From a first-order approximation, it can be shown that the liquid-vapor interface thermal resistance ( $\left.1 / h_{\text {evap }} A_{i}\right)$ is equivalent to that offered by the wick structure itself ( wick thickness $/\left(k_{\text {wick }} A_{i}\right)$ ) when the wick thickness is $40 \mu \mathrm{m}$ (calculated with $h_{\text {evap }}=10^{6} \mathrm{~W} / \mathrm{m}^{2} \mathrm{~K}$ for $\hat{\sigma}=1, k_{\text {wick }}=40 \mathrm{~W} / \mathrm{mK}$ ). $h_{\text {evap }}$ is much smaller $\left(\sim 10^{4} \mathrm{~W} / \mathrm{m}^{2} \mathrm{~K}\right)$ for $\hat{\sigma}=0.03$ and so the interface thermal resistance becomes significant in comparison to the wick resistance for even thicker wicks $(\sim 4 \mathrm{~mm})$ when $\hat{\sigma}=0.03$. Also, the wick thermal resistance decreases when the wick thermal conductivity is increased and it is no longer the controlling thermal resistance in vapor chamber operation. An accurate determination of the interface thermal resistance becomes increasingly important for thinner wicks of high thermal conductivity. Novel wick structures containing metallic nanowires and carbon nanotubes [37], have been proposed recently. In this section, the numerical simulations are repeated for the same vapor chamber geometry described in the previous section except with a thinner wick $(50 \mu \mathrm{m})$ and higher wick thermal conductivity $(176.3$ $\mathrm{W} / \mathrm{mK}$ ). The thermal conductivity of the solid in the porous wick medium is set to be $400 \mathrm{~W} / \mathrm{mK}$. Some novel wick microstructures, such as carbon nanotubes and metallic nanowires, have been shown [38, 39] to possess such high values of thermal conductivity. Also, the wick permeability is taken to be $2.97 \times 10^{-10}$ $\mathrm{m}^{2}$. All other properties and boundary conditions for the vapor chamber are kept the same as discussed in the previous section. 
Figure 11(a) and (b) show the temperature contours in the vapor chamber and velocity magnitude contours in the vapor core of the device. The temperature on the outer wall of the vapor chamber is plotted in Figure 11(c). Results in Figure 11 correspond to the coupled model and an accommodation coefficient of 0.03 . For this case, the liquid pressure drop inside the wick structure is $524 \mathrm{~Pa}$ while the steady-state operating pressure of the device is $29.4 \mathrm{kPa}$.

For $\hat{\sigma}=1$, the temperature drops across the vapor chamber predicted by the coupled and noncoupled models are $0.11 \mathrm{~K}$ and $0.13 \mathrm{~K}$, respectively. Hence, the non-coupled model over-predicts the temperature drop by $\sim 15 \%$. For $\hat{\sigma}=0.03$, the temperature drops across the vapor chamber as predicted by the coupled and non-coupled models are $1.49 \mathrm{~K}$ and $1.18 \mathrm{~K}$, respectively. This shows that the noncoupled model under-predicts the temperature drop across the vapor chamber by $\sim 26 \%$. Figure 12 (a) presents the interfacial pressure drop and the local contact angle along the liquid-vapor interface in the vapor chamber for $\hat{\sigma}=0.03$. The interfacial pressure drop (524 Pa) is highest at the center of the evaporator section, leading to the highest curvature and the smallest contact angle $\left(55.7^{\circ}\right)$ at this location. Again, the contact angle increases from $55.7^{\circ}$ in the evaporator section to $90^{\circ}$ at the center of the condenser region (i.e., at the wet point). Figure 12(b) shows the mass flux correction, area correction and mass flow rate correction ratios along the liquid-vapor interface in the vapor chamber for $\hat{\sigma}=0.03$. The corrections in interface area and mass flow rate are highest at the point of highest curvature and lowest contact angle, i.e., the center of the evaporator region (point 1). Again, the corrections become smaller as the condenser section is approached since the meniscus curvature in the wick pore decreases from the evaporation center to the center of condenser region.

\section{CONCLUSIONS}

A three-dimensional numerical model for flat heat pipes which accounts for the effect of wick structure in determining the evaporation rate at the liquid-vapor interface is developed. A device-level macro-model is coupled with a wick-level micro-model. This coupling leads to corrections to the evaporative mass flow rates at the liquid-vapor interface in the wick pore as well as to the interfacial area. These corrections are based on the local contact angle of liquid in the wick structure, and change along the location in the vapor chamber. Due to this coupling, thin-film evaporation, meniscus curvature effects, and Marangoni convection effects on the heat transfer rate from the liquid-vapor interface are accounted for in the device-level macro-model.

Flow and temperature fields in a two-dimensional flat heat pipe/vapor chamber are computed using the original macro-model and the coupled macro-model. The simulations are performed for two different values of the accommodation coefficient of the working fluid, viz., 0.03 and 1 . From the results obtained using the coupled and non-coupled model, it is inferred that the thermal resistance offered by the 
liquid-vapor interface inside the vapor chamber may become significant and affects the performance of the vapor chamber as the device is miniaturized, and as novel high-conductivity thin wicks become available. In these situations, the transport effects at the liquid-vapor interface must be correctly incorporated in order to accurately predict the performance of the vapor chamber. The need for a coupled model becomes imperative when (a) the thickness of the wick structure is very small (in the order of 100 $\mu \mathrm{m})$, (b) the thermal conductivity of wick structure is very high ( $>100 \mathrm{~W} / \mathrm{mK})$, or (c) when the accommodation coefficient of the working fluid is very small $(<0.1)$. The basic methodology developed in this work is applicable to other types of microstructures, operating conditions and device designs as well.

\section{Acknowledgement}

Support for this work from the Defense Advanced Research Projects Agency (DARPA) and Space and Naval Warfare Systems Center (SPAWAR/SYSCEN) San Diego, CA under Contract No. N66001-08-C2001 is gratefully acknowledged.

\section{REFERENCES}

[1] R. Ranjan, J. Y. Murthy and S. V. Garimella, Analysis of the Wicking and Thin-film Evaporation Characteristics of Wick Microstructures, ASME Journal of Heat Transfer 131 (2009) 101001 (1-11).

[2] R. Ranjan, J. Y. Murthy and S. V. Garimella, A Numerical Study of Evaporation Heat Transfer from Liquid-Vapor Interface in Wick Microstructure, 2009 ASME International Mechanical Engineering Congress and Exposition, November 13-19, Orlando, FL, paper no. 11326.

[3] S. V. Garimella and C. B. Sobhan, Recent Advances in the Modeling and Applications of Nonconventional Heat Pipes, Advances in Heat Transfer, 35 (2001) 249-308.

[4] U. Vadakkan, S. V. Garimella and J. Y. Murthy, Transport in Flat Heat Pipes at High Fluxes from Multiple Discrete Sources, ASME Journal of Heat Transfer 126 (2004) 347-354.

[5] U. Vadakkan, J. Y. Murthy and S. V. Garimella, Transient Analysis of Flat Heat Pipes, Procs. ASME Summer Heat Transfer Conference, July 21-23, Las Vegas, Nevada, 2003.

[6] V. Ooijen and C. J. Hoogendoorn, Vapor Flow Calculations in a Flat Heat Pipe, AIAA Journal 17 (1979) 1251-1259.

[7] J. M. Tournier and M. S. El-Genk, A Heat Pipe Transient Analysis Model, International Journal of Heat and Mass Transfer 37 (1993) 753-762.

[8] N. Zhu and K. Vafai, Analytical Modeling of the Startup Characteristics of Asymmetrical Flat-plate and Disk-shaped Heat Pipes, International Journal of Heat and Mass Transfer 41(17) (1998) 2619-2637. 
[9] G. Carbajal, C. B. Sobhan, G. P. Peterson, D. T. Queheillalt, H. N. G. Wadley, A Quasi-3D Analysis of the Thermal Performance of a Flat Heat Pipe, International Journal of Heat and Mass Transfer 50 (2007) 4286-4296.

[10] Y. Koito, H. Imura, M. Mochizuki, Y. Saito and S. Torii, Numerical Analysis and Experimental Verification on Thermal Fluid Phenomena in a Vapor Chamber, Applied Thermal Engineering 26 (2006) 1669-1676.

[11] K. H. Do, S. J. Kim and Suresh V. Garimella, A Mathematical Model for Analyzing the Thermal Characteristics of a Flat Micro Heat Pipe with a Grooved Wick, International Journal of Heat and Mass Transfer 51(19-20) (2008) 4637-4650.

[12] B. Xiao and A. Faghri, A Three-dimensional Thermal-fluid Analysis of Flat Heat Pipes, International Journal of Heat and Mass Transfer 51 (2008) 3113-3126.

[13] R. Singh, A Akbarzadeh and M. Mochizuki, Effect of Wick Characteristics on the Thermal Performance of the Miniature Loop Heat Pipes, ASME Journal of Heat Transfer 131 (2009) 082601 (110).

[14] Y. Chen, C. Zhang, M. Shi, J. Wu and G. P. Peterson, Study on Flow and Heat Transfer Characteristics of Heat Pipe with Axial Omega-shaped Microgrooves, International Journal of Heat and Mass Transfer 52 (3-4) (2008) 636-643.

[15] M. Ghajar, J. Darabi and N. Crews Jr, A Hybrid CFD-mathematical Model for Simulation of a MEMS Loop Heat Pipe for Electronics Cooling Applications, Journal of Micromechanics and Microengineering 15 (2005) 313-321.

[16] J. Rice and A. Faghri, Analysis of Screen Wick Heat Pipes, Including Capillary Dry-out Limitations, Journal of Thermophysics and Heat Transfer 21(3) (2007) 475-486.

[17] R. Savino and S. Fico, Buoyancy and Surface Tension Driven Convection around a Bubble, Physics of Fluids 18 (2006) 057104(1-14).

[18] M. Behnia, F. Stella and G. Guj, A Numerical Study of Three-dimensional Combined Buoyancy and Thermocapillary Convection, International Journal of Multiphase Flow 21(3) (1995) 529-542.

[19] C. A. Ward and F. Duan, Turbulent Transition of Thermocapillary Flow Induced by Water Evaporation, Physical Review E 69 (2004) 056308(1-10).

[20] H. Wang, S. V. Garimella and J. Y. Murthy, "Characteristics of an Evaporating Thin Film in a Microchannel,” International Journal of Heat and Mass Transfer, vol. 50, pp. 3933-3942, 2007.

[21] R. Ranjan, J. Y. Murthy, S. V. Garimella, A Microscale Model for Thin-film Evaporation in Capillary Wick Structures, International Journal of Heat and Mass Transfer (in press). 
[22] R. W. Schrage, A Theoretical Study of Interface Mass Transfer, New York: Columbia University Press, (1953).

[23] M. Bond, H. Struchtrup, Mean evaporation and condensation coefficient based on energy dependent condensation probability, Phys. Rev. E 70(6) (2004) 061605(1-21).

[24] R. Marek, J. Straub, Analysis of the evaporation coefficient and the condensation coefficient of water, International Journal of Heat and Mass Transfer 44 (2001) 39-53.

[25] K. Hickman, Maximum evaporation coefficient of water, Ind. Eng. Chem. 46(7) (1954) 13-29.

[26] V. P. Carey, Liquid-Vapor Phase Change Phenomena, Hemisphere Publishing Corp., Washington DC.

[27] A. Faghri, Heat Pipe Science and Technology, Taylor and Francis, Washington DC, (1995).

[28] G. Barnes, Insoluble monolayers and the evaporation coefficient of water, Journal of Colloid and Interface Science 65(2) (1978) 567-572.

[29] H. Mendelson, S. Yerazunis, Mass transfer at high mass fluxes: PartI. Evaporation at the stagnation point of a cylinder, AIChE Journal 11(5) (1965) 834-840.

[30] V. K. Badam, V. Kumar, F. Durst, and D. Danov, Experimental and Theoretical Investigations on Interfacial Temperature Jumps during Evaporation, Experimental Thermal and Fluid Sciences 32 (2007) 276-292.

[31] J. W. Rose, Interphase matter transfer, the condensation coefficient and dropwise condensation, Proc. 11th Int. Heat Transfer Conf., Kyongju, Korea 1 (1998) 89-104.

[32] S. V. Patankar, Numerical Heat Transfer and Fluid Flow, Hemisphere, Washingtom (1980).

[33] Fluent Inc., Fluent 6.2 User's Guide, (2004).

[34] K. A. Brakke, The Surface Evolver, Experimental Mathematics 1(2) (1992) 141-165.

[35] Y. A. Cengel, Heat Transfer: A Practical Approach, WCB/McGraw-Hill (1998).

[36] MATLAB 2007 a, The Mathworks, Natick, MA USA.

[37] Q. Cai, C. L. Chen, Design and Test of Carbon Nanotube Biwick Structure for High-Heat-Flux Phase Change Heat Transfer, ASME Journal Heat Transfer 132(5) (2010) 052403.

[38] S. Berber, Y-K. Kwon, and D. Tomanek, Unusually High Thermal Conductivity of Carbon Nanotubes, Physical Review Letters 84(20) (2000) 4613.

[39] P. Kim, L. Shi, A. Majumdar, and P. L. McEuen, Thermal Transport Measurements of Individual Multiwalled Nanotubes, Physical Review Letters, 87(21) (2001) 215502. 


\section{LIST OF TABLES}

Table 1. Thermophysical properties of the heat pipe material and the working fluid.

\section{LIST OF FIGURES}

Figure 1. (a) Schematic diagram of a flat heat pipe with a sintered powder wick structure. The insets shows how the meniscus curvature changes from the evaporator to the condenser;

(b) shape of water meniscus formed between parallel wires ( itch $=3.56 \times$ radius, $\theta=$ $\left.30^{\circ}\right)$; (c) illustration of boundary conditions for $2 \mathrm{D}$ liquid meniscus formed between horizontal wires.

Figure 2. Temperature contours $(\mathrm{K})$ and flow streamlines in the solid and liquid domains for a meniscus formed between parallel copper wires (a) $\hat{\sigma}=0.03$, (b) $\hat{\sigma}=1$ ( $T_{\text {vap }}=298 \mathrm{~K}$, $T_{\text {inlet }}=T_{b o t}=300.5 \mathrm{~K}, \varepsilon=0.56, \theta=5^{\circ}$, radius $\left.=100 \mu \mathrm{m}\right)$; (c) evaporative mass flux (Eqn. 9) plotted on the interface (from solid-liquid contact line towards the center of the meniscus) for $\hat{\sigma}=0.03$ and 1 .

Figure 3. (a) Temperature contours in the liquid domain for evaporation from a pool of liquid, $T_{v a p}$ $=298 \mathrm{~K}, T_{\text {inlet }}=300.5 \mathrm{~K}$, domain width $=178 \mu \mathrm{m}$, height $=100 \mu \mathrm{m}$; (b) evaporation heat transfer coefficient and total evaporation rate as a function of accommodation coefficient.

Figure 4. Non-dimensional effective pore radius of a screen mesh wick as a function of contact angle $(\theta)$ for various porosities $(\varepsilon)$.

Figure 5. Temperature contours in the liquid and solid domains for the liquid meniscus formed in a wick pore and those in the liquid domain under a flat meniscus; $T_{\text {inlet }}=T_{b o t}=300.5 \mathrm{~K}, T_{v}$ $=298 \mathrm{~K}$.

Figure 6. (a) Meniscus area ratio $\left(A_{\text {curved }} / A_{\text {flat }}\right)$ and (b, c) mass flux ratio $\left(m_{\text {curved }}^{\prime \prime} / m_{\text {flat }}^{\prime \prime}\right)$ as functions of contact angle $(\theta)$ for various porosities $(\varepsilon)$; (b) and (c) correspond to $\hat{\sigma}=0.03 \hat{\sigma}=1$, respectively $\left(T_{\text {bot }}=T_{\text {inlet }}=300.5 \mathrm{~K}, T_{v}=298 \mathrm{~K}\right)$.

Figure 7. (a) Schematic diagram of the flat heat pipe (vapor chamber) modeled in the present work; $(\mathrm{b}, \mathrm{c})$ temperature contours $(\mathrm{K}),(\mathrm{d}, \mathrm{e})$ velocity contours in the vapor core $(\mathrm{m} / \mathrm{s})$, and $(\mathrm{f}, \mathrm{g})$ velocity contours $(\mathrm{m} / \mathrm{s})$ in the wick region of the vapor chamber input heat flux $=10$ $\mathrm{W} / \mathrm{cm}^{2}$ for $(\mathrm{b}, \mathrm{d}, \mathrm{f}) \hat{\sigma}=1,(\mathrm{c}, \mathrm{e}, \mathrm{g}) \hat{\sigma}=0.03$.

Figure 8. (a, b)Temperature on outer walls of the vapor chamber; (c, d) evaporation/condensation mass flow rates on the upper and lower wick-vapor interfaces; (a, c) and (b, d) correspond to $\hat{\sigma}=1$ and $\hat{\sigma}=0.03$ respectively; positive phase-change mass flux represents condensation.

Figure 9. (a, b) Interfacial capillary pressure drop and local contact angle (c, d) mass flux correction, area correction and mass flow rate correction ratios along the liquid-vapor interfaces of the vapor chamber; (a, c) and (b, d) correspond to $\hat{\sigma}=1$ and $\hat{\sigma}=0.03$ respectively; points 1, 2, 3 and 4 correspond to the various locations shown in the vapor chamber in Figure 7 (a).

Figure 10.(a) Temperature contours (K) in the vapor chamber predicted by the coupled micro-macro model, (b) temperature (K) on the outer walls of the vapor chamber; for $\hat{\sigma}=0.03$.

Figure 11.(a) Temperature contours (K), (b) velocity contours $(\mathrm{m} / \mathrm{s})$ in the vapor core of the vapor chamber, and (c) temperature $(\mathrm{K})$ on the outer walls of the vapor chamber; predicted by the coupled model for $\hat{\sigma}=0.03$.

Figure 12.(a) Interfacial capillary pressure drop and local contact angle (b) mass flux correction, area correction and mass flow rate correction ratios along the liquid-vapor interfaces of the vapor chamber; for $\hat{\sigma}=0.03$. 
Table 1. Thermophysical properties of the heat pipe material and the working fluid.

\begin{tabular}{|c|c|c|}
\hline Copper wall/wick & $\begin{array}{l}\text { Thermal conductivity } \\
\text { Specific heat } \\
\text { Density } \\
\text { Thermal conductivity of the } \\
\text { wick }\end{array}$ & $\begin{array}{l}387.6 \mathrm{~W} / \mathrm{m} \mathrm{K} \\
381 \mathrm{~J} / \mathrm{kg} \mathrm{K} \\
8978 \mathrm{~kg} / \mathrm{m}^{3} \\
40 \mathrm{~W} / \mathrm{m} \mathrm{K}^{2}\end{array}$ \\
\hline Water & $\begin{array}{l}\text { Thermal conductivity } \\
\text { Specific heat } \\
\text { Density } \\
\text { Viscosity }\end{array}$ & $\begin{array}{l}0.6 \mathrm{~W} / \mathrm{m} \mathrm{K} \\
4182 \mathrm{~J} / \mathrm{kg} \mathrm{K} \\
1000 \mathrm{~kg} / \mathrm{m}^{3} \\
8 \times 10^{-4} \mathrm{~N} \mathrm{~s}^{2} \mathrm{~m}^{2}\end{array}$ \\
\hline Water vapor & $\begin{array}{l}\text { Thermal conductivity } \\
\text { Specific heat } \\
\text { Density } \\
\text { Viscosity }\end{array}$ & $\begin{array}{l}0.026 \mathrm{~W} / \mathrm{m} \mathrm{K} \\
2014 \mathrm{~J} / \mathrm{kg} \mathrm{K} \\
0.01 \mathrm{~kg} / \mathrm{m}^{3} \\
8.49 \times 10^{-6} \mathrm{~N} \\
\mathrm{~s} / \mathrm{m}^{2}\end{array}$ \\
\hline Water/vapor & Latent heat of vaporization & $2446.36 \mathrm{~kJ} / \mathrm{kg}$ \\
\hline
\end{tabular}




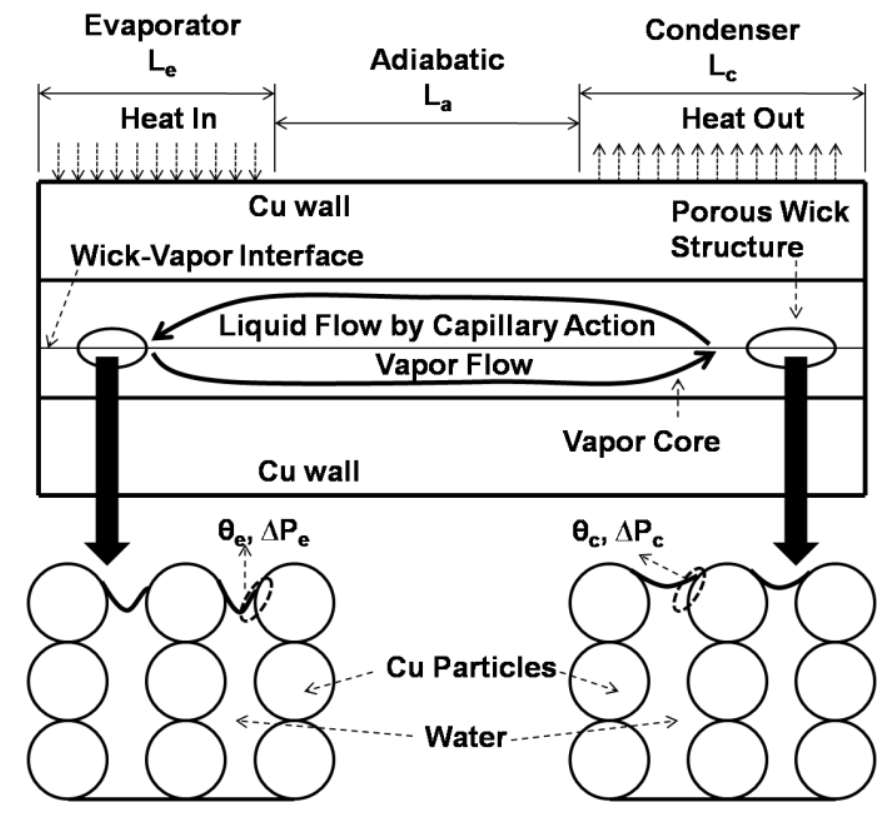

(a)

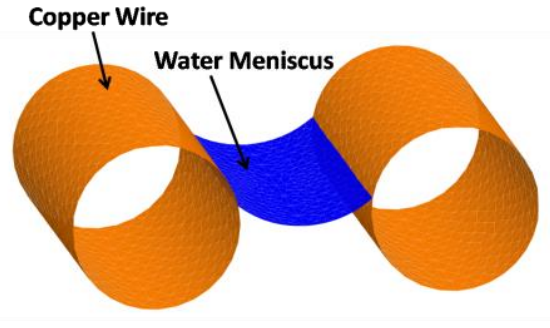

(b)

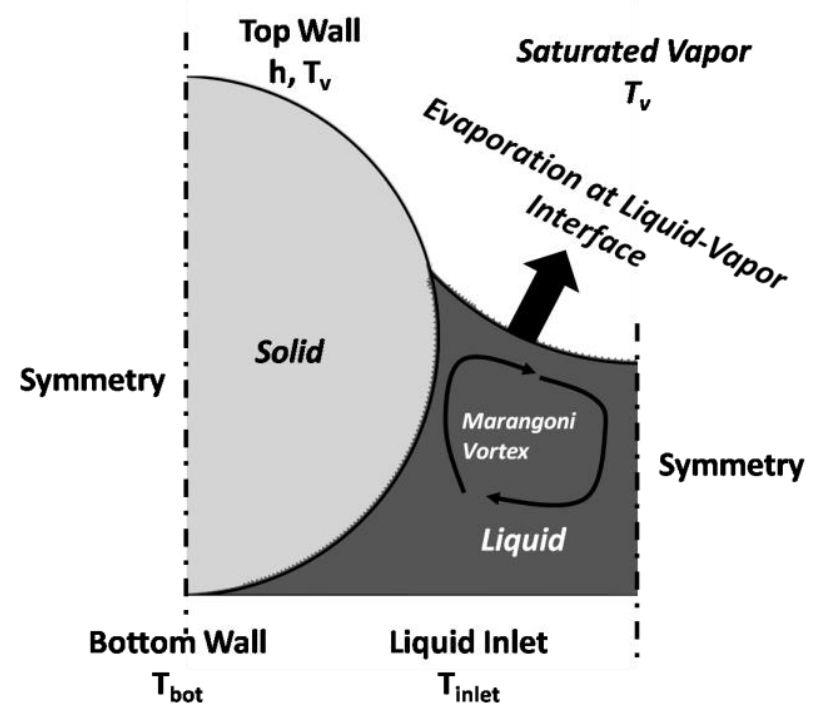

(c)

Figure 1. (a) Schematic diagram of a flat heat pipe with a sintered powder wick structure. The insets shows how the meniscus curvature changes from the evaporator to the condenser; (b) shape of water meniscus formed between parallel wires ( pitch $=3.56 \times$ radius, $\theta=30^{\circ}$ ); (c) illustration of boundary conditions for 2D liquid meniscus formed between horizontal wires. 


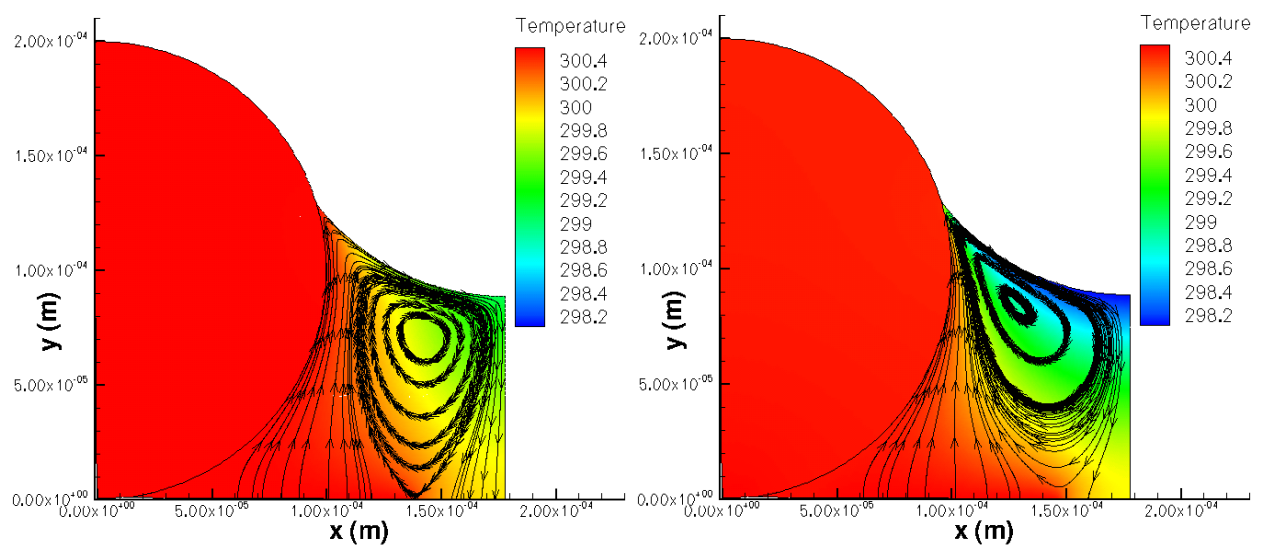

(a)

(b)

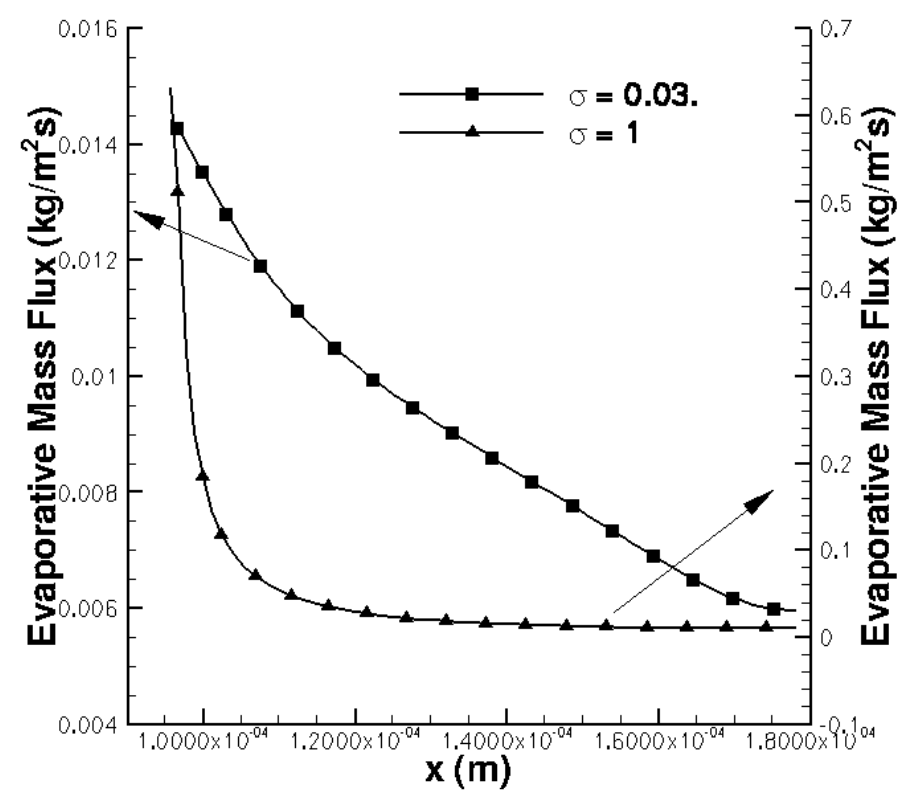

Figure 2. Temperature contours (K) and flow streamlines in the solid and liquid domains for a meniscus formed between parallel copper wires (a) $\hat{\sigma}=0.03$, (b) $\hat{\sigma}=1\left(T_{\text {vap }}=298 \mathrm{~K}, T_{\text {inlet }}=T_{\text {bot }}=\right.$ $300.5 \mathrm{~K}, \varepsilon=0.56, \theta=5^{\circ}$, radius $=100 \mu \mathrm{m}$ ); (c) evaporative mass flux (Eqn. 9) plotted on the interface (from solid-liquid contact line towards the center of the meniscus) for $\hat{\sigma}=0.03$ and 1 . 


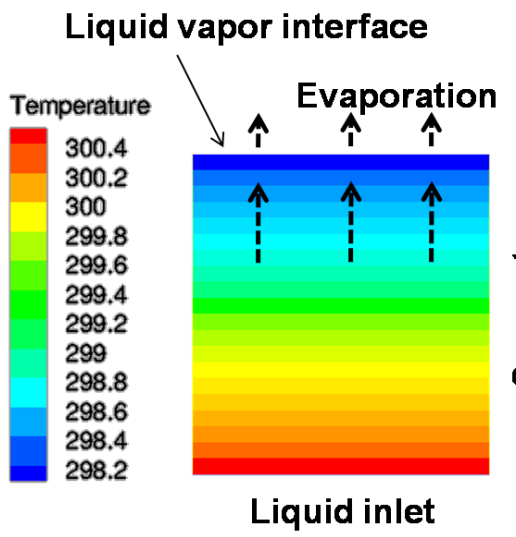

(a)

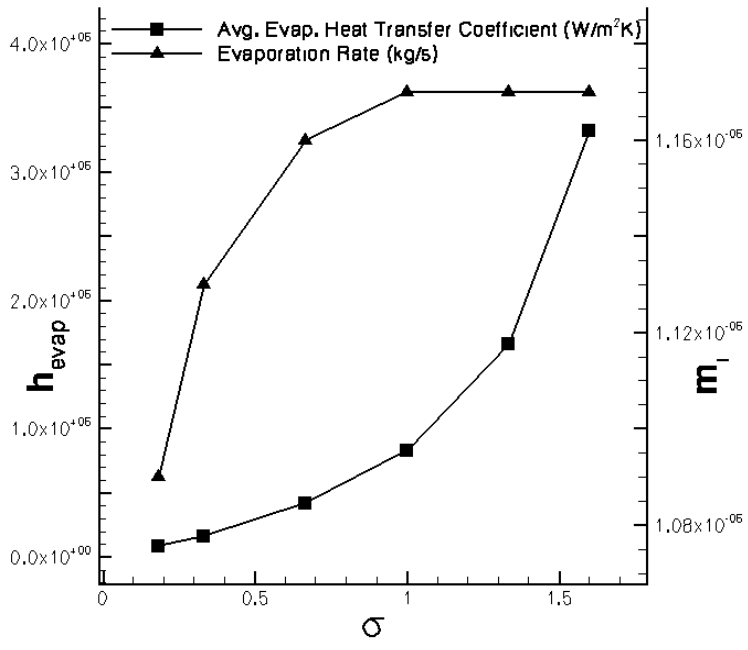

(b)

Figure 3. (a) Temperature contours in the liquid domain for evaporation from a pool of liquid, $T_{v a p}$ $=298 \mathrm{~K}, T_{\text {inlet }}=300.5 \mathrm{~K}$, domain width $=178 \mu \mathrm{m}$, height $=100 \mu \mathrm{m}$; (b) evaporation heat transfer coefficient and total evaporation rate as a function of accommodation coefficient. 


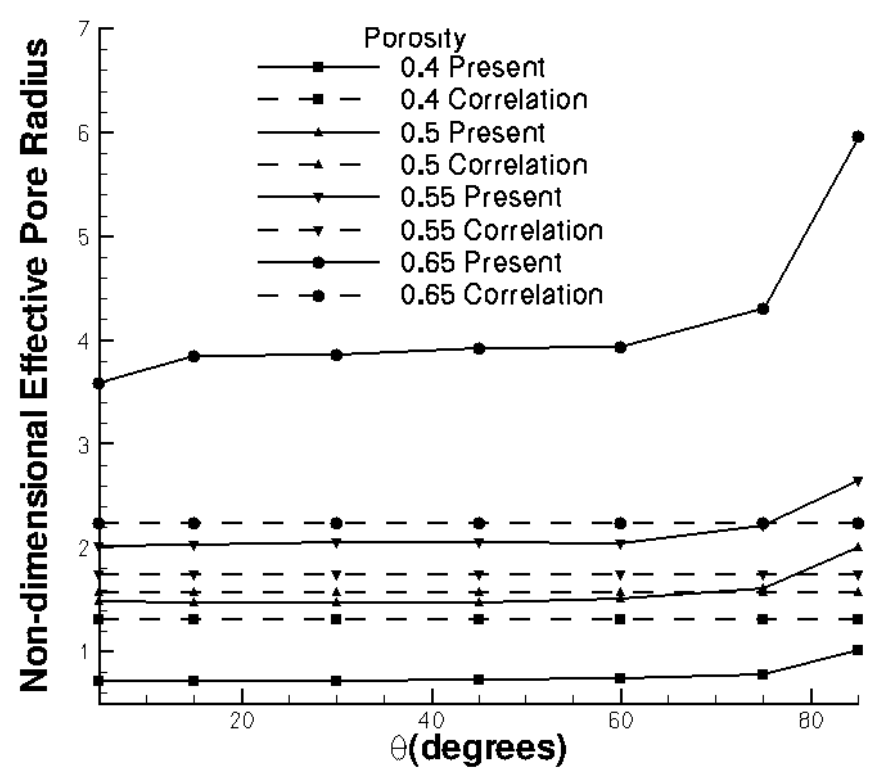

Figure 4. Non-dimensional effective pore radius of a screen mesh wick as a function of contact angle $(\theta)$ for various porosities $(\varepsilon)$. Dashed lines represent values computed using Ref. [27] 


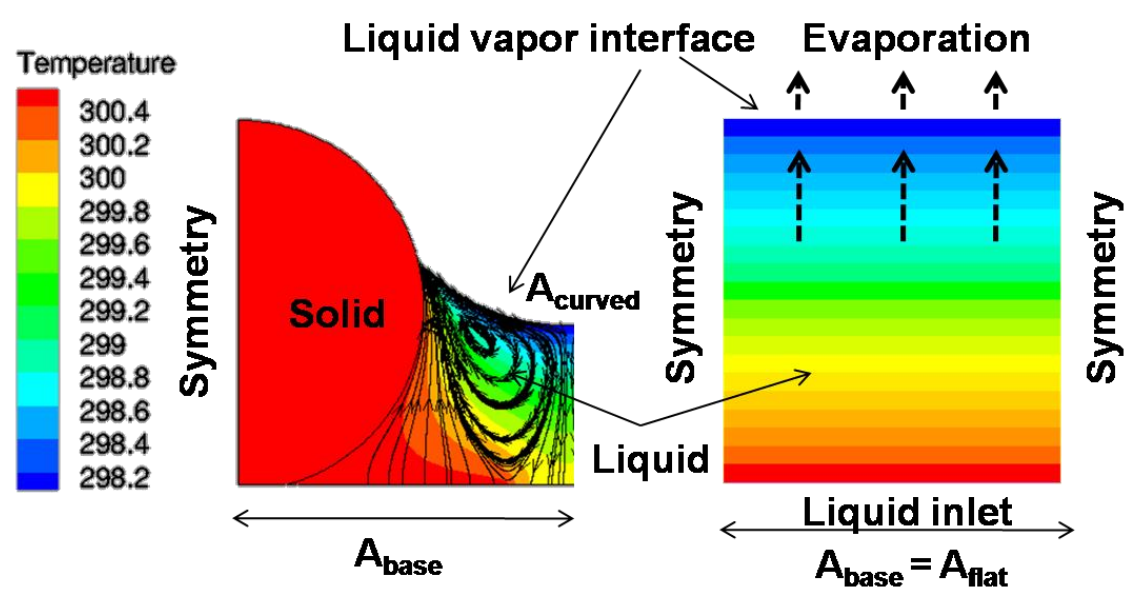

Figure 5. Temperature contours in the liquid and solid domains for the liquid meniscus formed in a wick pore and those in the liquid domain under a flat meniscus; $T_{\text {inlet }}=T_{b o t}=300.5 \mathrm{~K}, T_{v}=298 \mathrm{~K}$. 


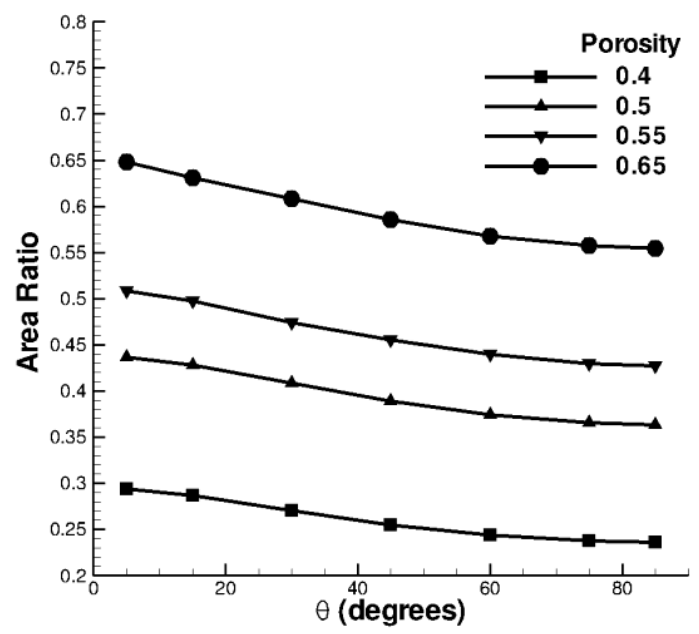

(a)

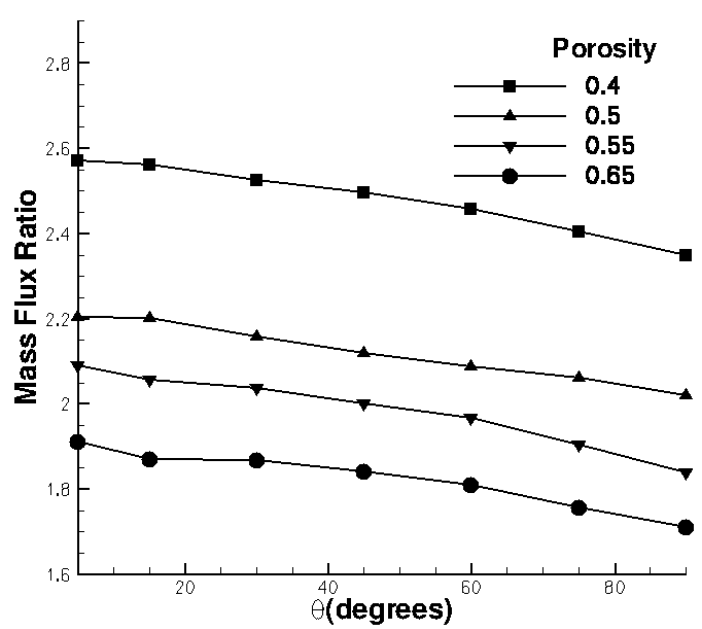

(b)

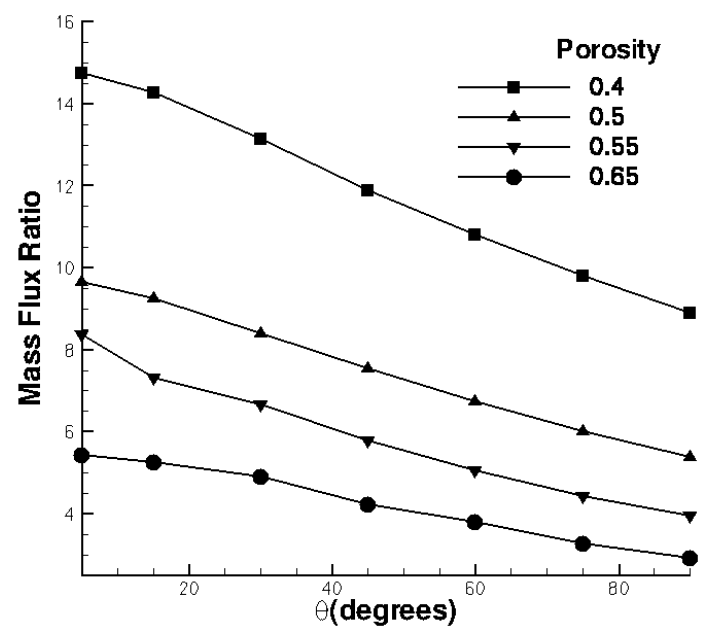

(c)

Figure 6. (a) Meniscus area ratio $\left(A_{\text {curved }} / A_{\text {flat }}\right)$, and (b, c) mass flux ratio $\left(m_{\text {curved }}^{\prime \prime} / m_{\text {flat }}^{\prime \prime}\right)$ as functions of contact angle $(\theta)$ for various porosities $(\varepsilon)$; (b) and (c) correspond to $\hat{\sigma}=0.03$ and $\hat{\sigma}=$ 1 , respectively $\left(T_{\text {bot }}=T_{\text {inlet }}=300.5 \mathrm{~K}, T_{v}=298 \mathrm{~K}\right)$. 


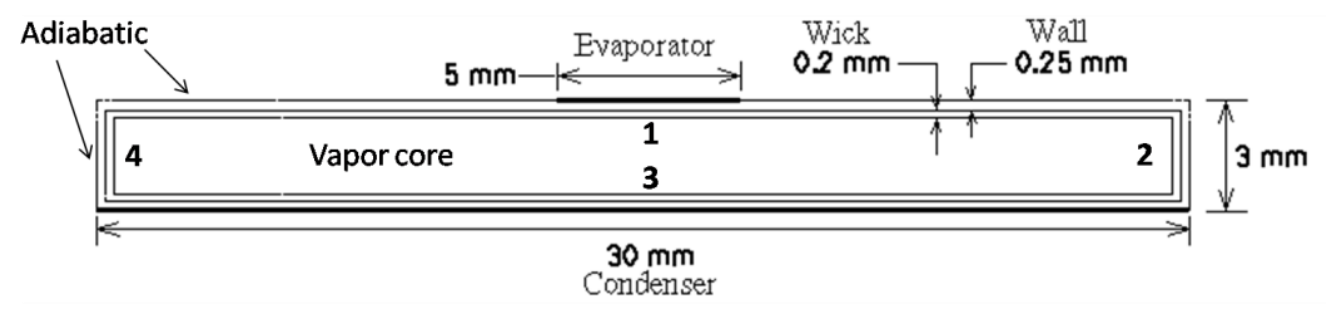

(a)

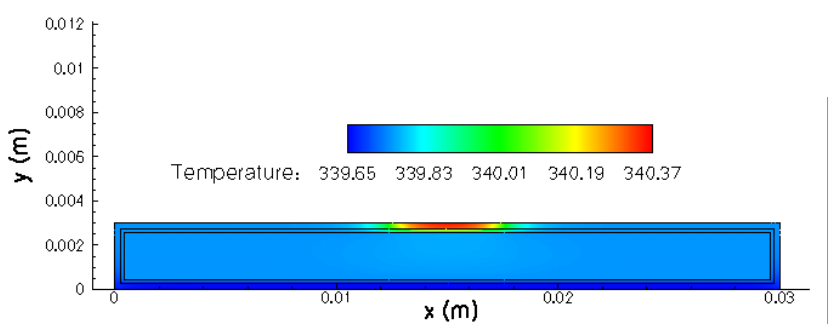

(b)

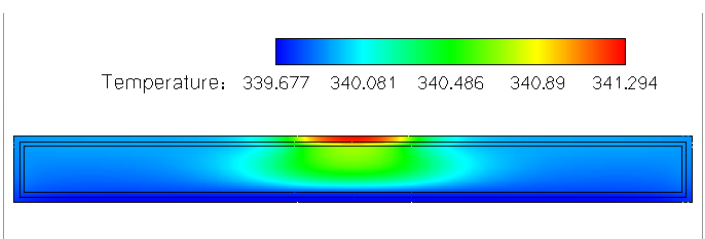

(c)

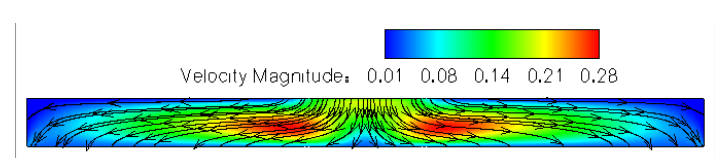

(d)

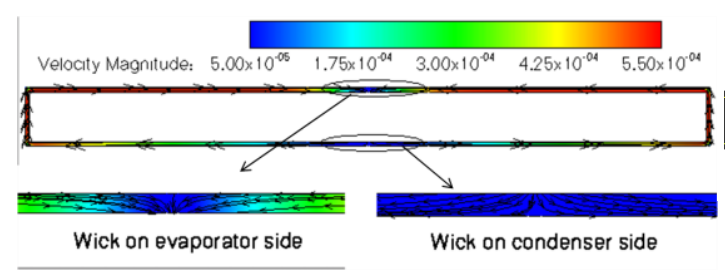

(f) (e)

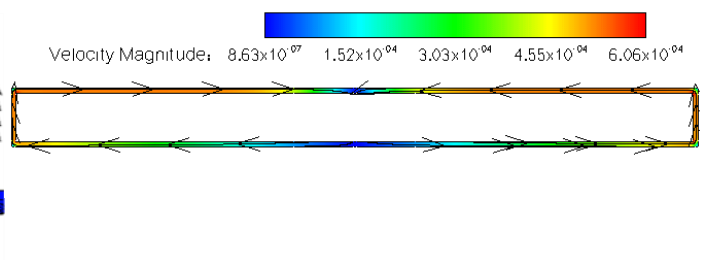

$(\mathrm{g})$

Figure 7. (a) Schematic diagram of the flat heat pipe (vapor chamber) modeled in the present work, $(b, c)$ temperature contours $(K),(d, e)$ velocity contours in the vapor core $(\mathrm{m} / \mathrm{s})$, and $(\mathrm{f}, \mathrm{g})$ velocity contours $(\mathrm{m} / \mathrm{s})$ in the wick region of the vapor chamber input heat flux $=10 \mathrm{~W} / \mathrm{cm}^{2}$ for $(\mathrm{b}, \mathrm{d}, \mathrm{f}) \hat{\sigma}=$

$$
1,(\mathrm{c}, \mathrm{e}, \mathrm{g}) \hat{\sigma}=0.03 \text {. }
$$




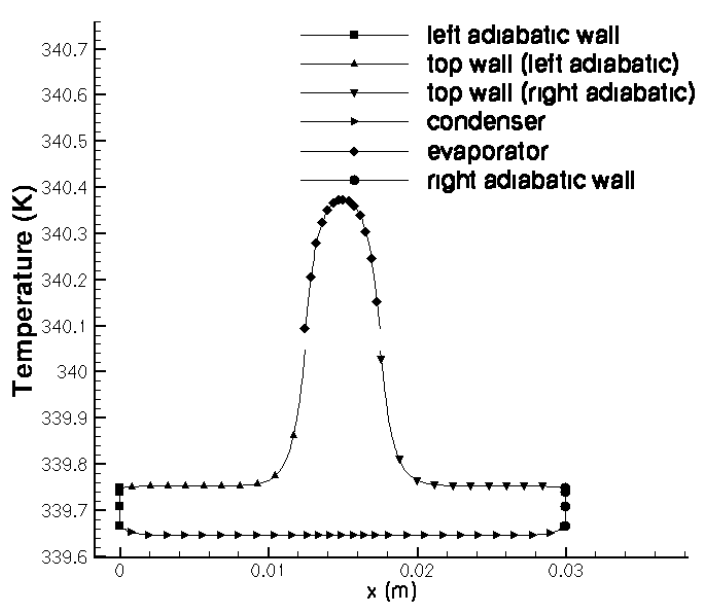

(a)

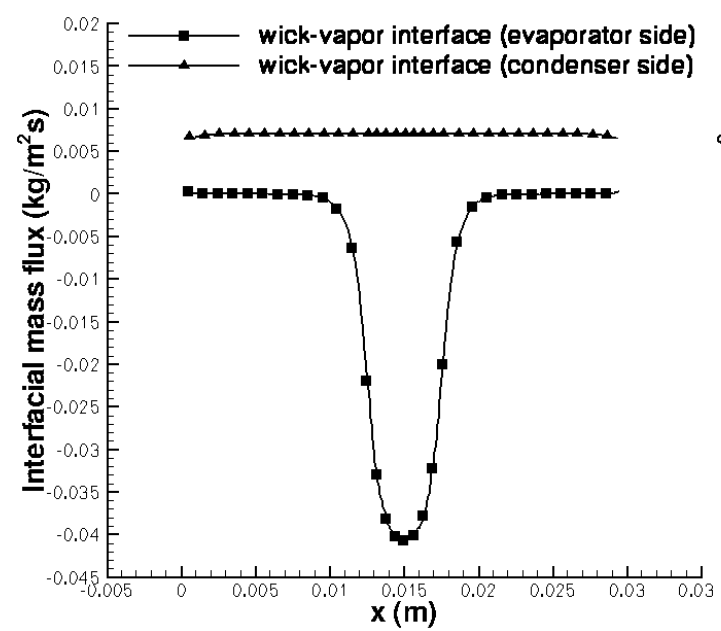

(c)

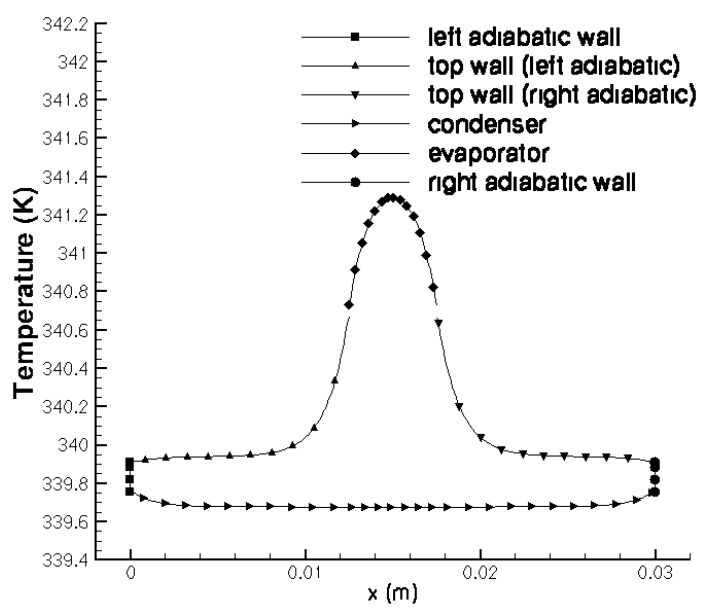

(b)

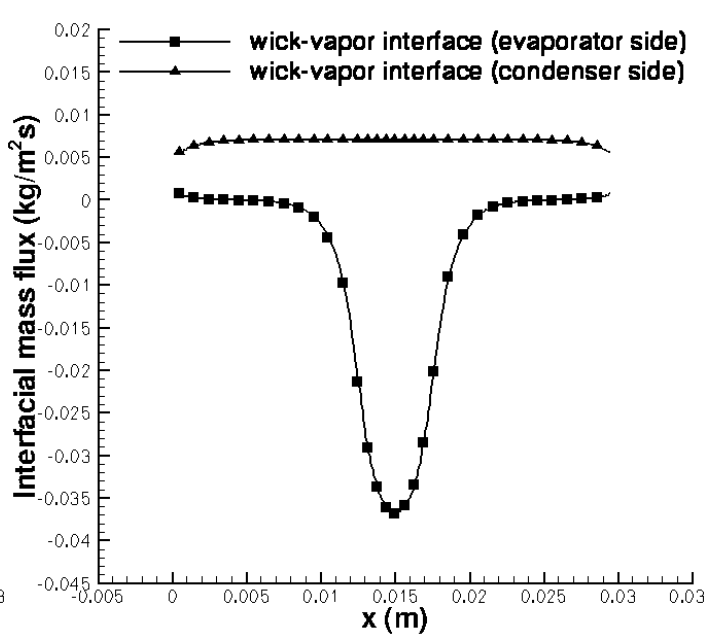

(d)

Figure 8. (a, b)Temperature on outer walls of the vapor chamber, and (c, d)

evaporation/condensation mass flow rates on the upper and lower wick-vapor interfaces; (a, c) and (b, d) correspond to $\hat{\sigma}=1$ and $\hat{\sigma}=0.03$ respectively; positive phase-change mass flux represents condensation. 


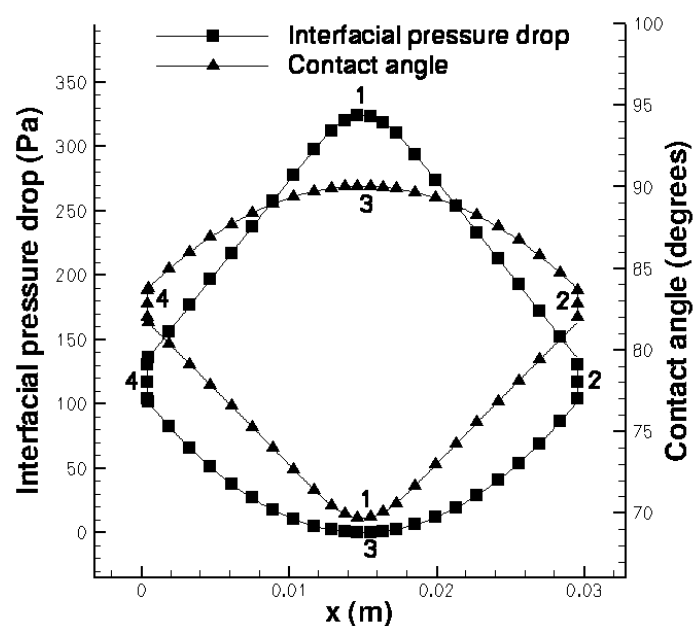

(a)

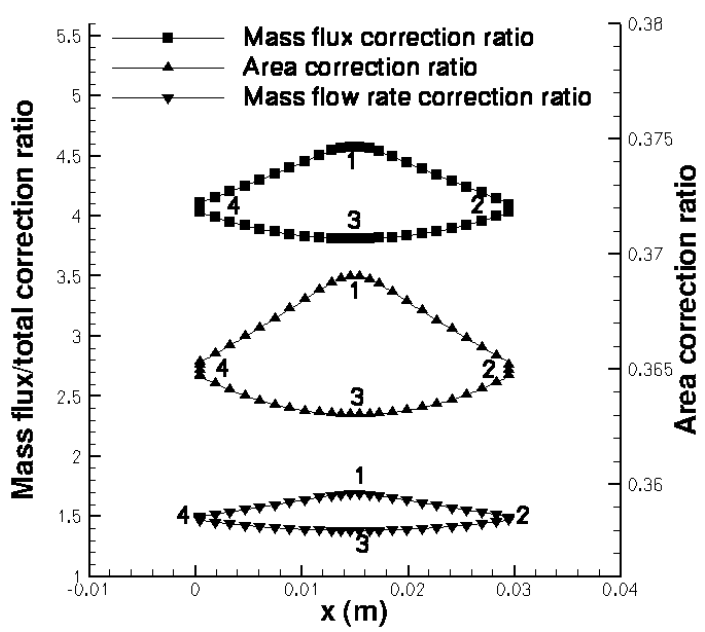

(c)

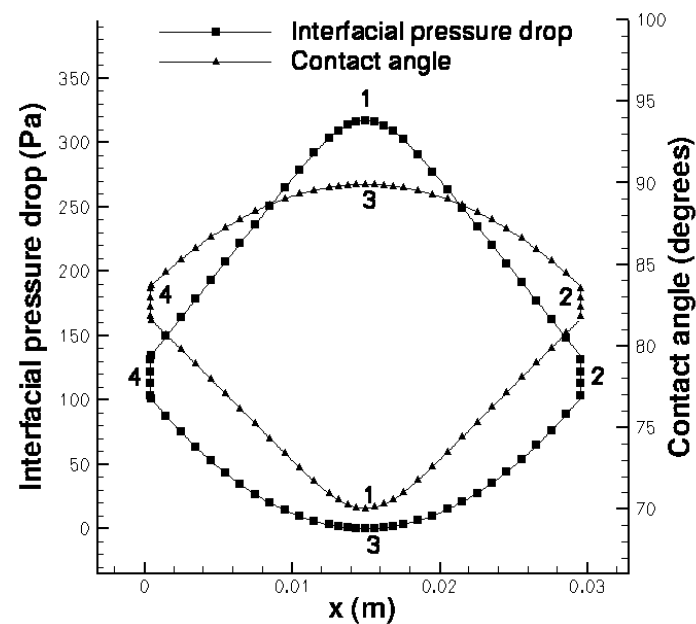

(b)

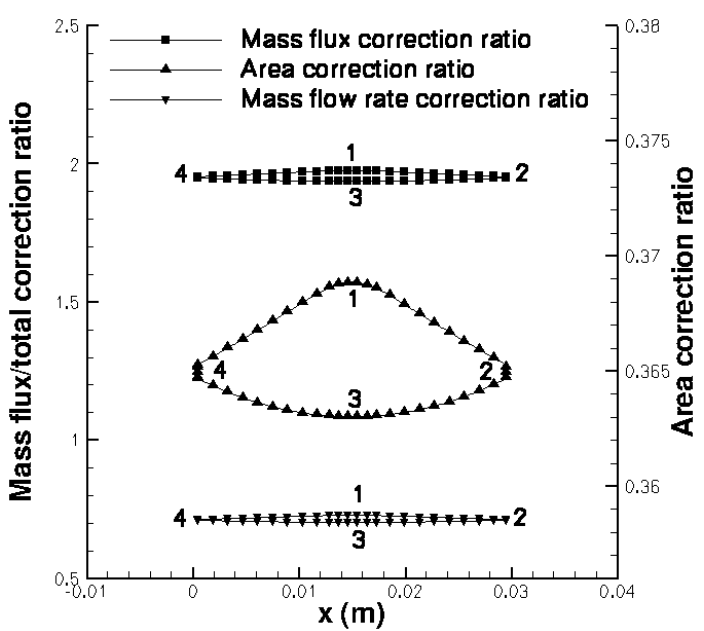

(d)

Figure 9. (a, b) Interfacial capillary pressure drop and local contact angle, and (c, d) mass flux correction, area correction and mass flow rate correction ratios along the liquid-vapor interface of the vapor chamber; (a,c) and (b,d) correspond to $\hat{\sigma}=1$ and $\hat{\sigma}=0.03$ respectively; points $1,2,3$ and 4 correspond to the various locations shown in the vapor chamber in Figure 7 (a). 


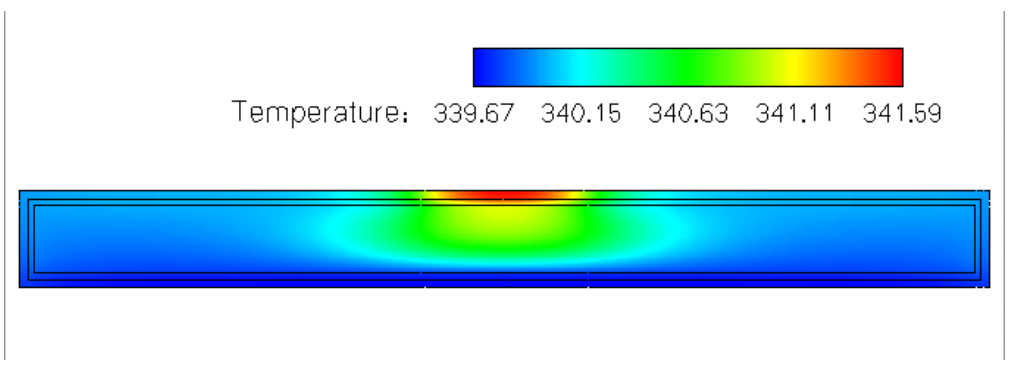

(a)

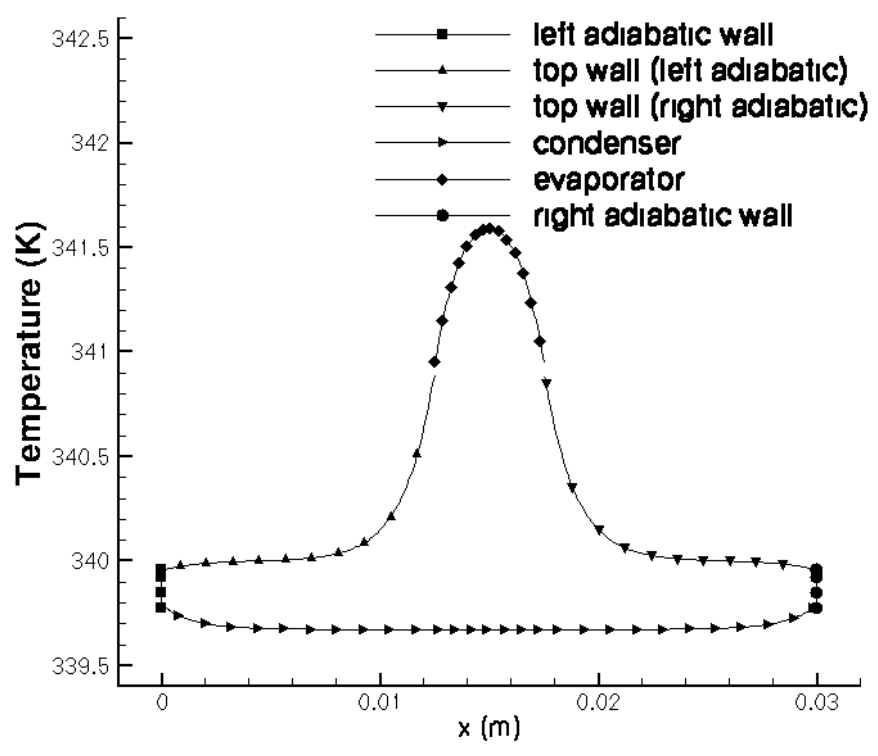

(b)

Figure 10. (a) Temperature contours (K) in the vapor chamber predicted by the coupled micromacro model, and (b) temperature $(\mathrm{K})$ on the outer walls of the vapor chamber; for $\hat{\sigma}=0.03$. 


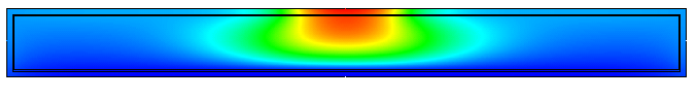

(a) (b)

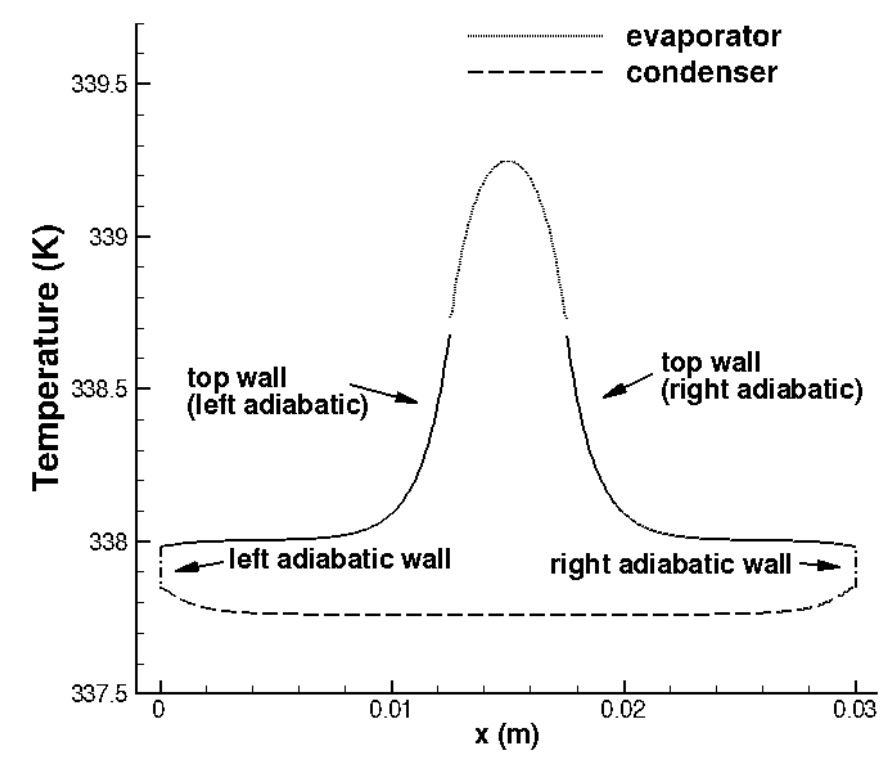

(c)

Figure 11. (a) Temperature contours $(\mathrm{K})$, (b) velocity contours $(\mathrm{m} / \mathrm{s})$ in the vapor core of the vapor chamber, and (c) temperature $(\mathrm{K})$ on the outer walls of the vapor chamber; predicted by the coupled model for $\hat{\sigma}=0.03$. 


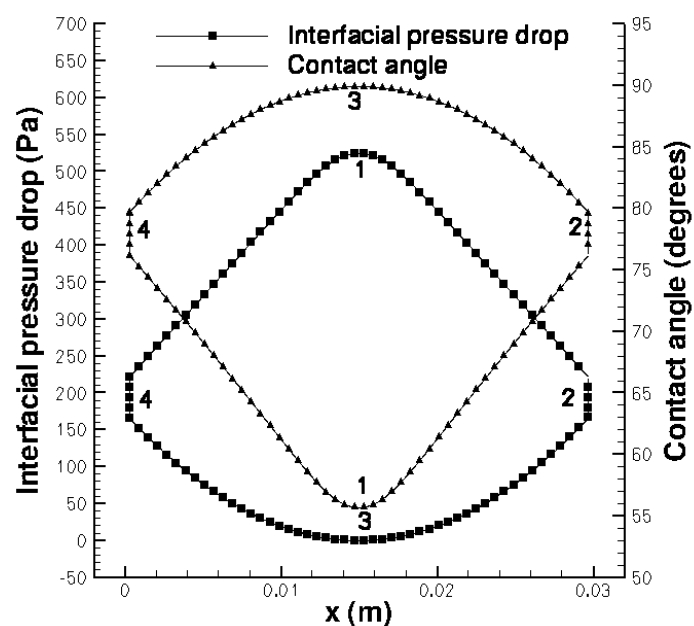

(a)

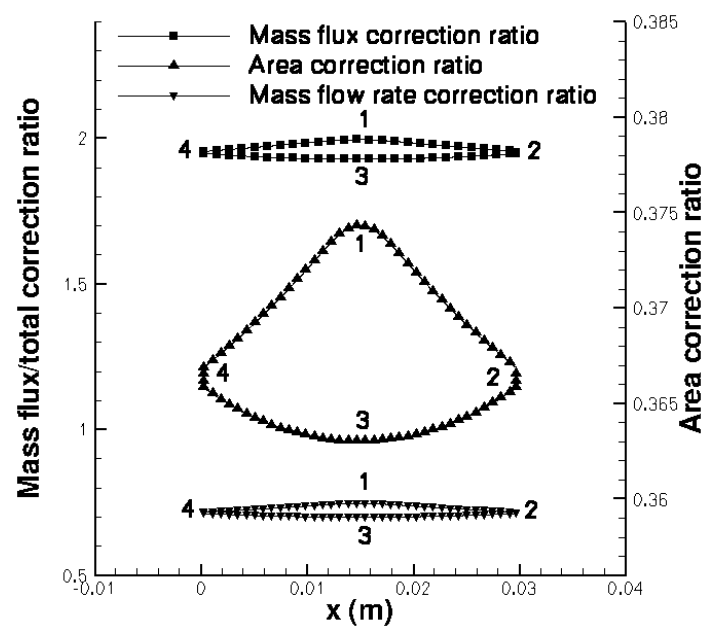

(b)

Figure 12. (a) Interfacial capillary pressure drop and local contact angle (b) mass flux correction, area correction and mass flow rate correction ratios along the liquid-vapor interfaces of the vapor chamber; for $\hat{\sigma}=0.03$. 